\title{
Can market power in the electricity spot market translate into market power in the hedge market?
}

\author{
Gabriel Fiuza de Bragança and Toby Daglish
}

August 6, 2012

\begin{abstract}
Electricity is a non-storable commodity frequently traded in complex markets characterized by oligopolistic structures and uniform-price auctions. These particularities confer to electricity prices idiosyncratic patterns not addressed by the usual commodity pricing literature. This paper allows for oligopoly, vertical integration and uniform-price auction and derives a linear equilibrium relationship between spot prices and state variables affecting firms' costs and demand under usual functional simplifications. It applies a two-factor forward pricing model over the equilibrium spot price process, and shows that forward prices can be positively affected by spot market power. Thus, hedge prices may be affected by market power as it appears in the spot market.
\end{abstract}




\section{Introduction}

A large portion of the energy traded in most competitive electricity markets is hedged. Forward and futures contracts frequently constitute the most significant hedging instruments. This section provides a closed-form solution to evaluate how concentration in the electricity generation industry impacts the forward price curve. Our hybrid pricing model also innovates by taking into account common features of electricity markets such as oligopoly, forward contracts, vertical integration and a uniform price auction mechanism. ${ }^{1}$ Here we address the problem in the opposite direction. We analyze how an increase in the spot market concentration can increase prices in the hedge market.

electricity is a non-storable commodity for which spot prices are characterized by the presence of strong seasonal patterns and short-lived trend deviations (spikes). Several papers start from these premises and take into account a broad array of stochastic processes to mimic this observed price behavior. They mostly rely on assumed storage possibilities and make use of no-arbitrage arguments to value derivatives. Schwartz (1997), Schwartz and Smith (2000) and Lucia and Schwartz (2002) concentrate on mean reverting behavior, long-term uncertainty and seasonality. On the other hand, Deng (2000) and Cartea and Villaplana (2005) focus on short-lived oscillations such as jump and spike features. However, these papers frequently rely on estimating non-observable state variables which is costly in terms of data quality and availability. Few equilibrium insights can be drawn from either of these models.

To overcome these disadvantages, a growing literature applies hybrid models to price derivatives. These models are composed of two basic stages. First they build on an equilibrium framework when explaining electricity price behavior in terms of observable state variables of demand and supply. Second, they assume a dynamic behavior for state variables and apply no-arbitrage methodologies to price derivatives. This approach offers economic insights into derivative pricing. In other words, derivatives are put in terms of demand and supply parameters.

Skantze, Gubina, and Ilić (2000), Barlow (2002), Pirrong and Jermakyan (2008), Cartea and Villaplana (2008) and Lyle and Elliott (2009) are representatives of this line of research. All these models are characterized by imposing a functional form, based on equilibrium assumptions, for the relationship between price and variables related to demand and supply. Barlow (2002) considers the existence of deterministic and strongly increasing marginal production costs and a stochastic aggregate demand. Skantze et al. (2000) consider the spot price as an exponential function of load and supply bid shifts, treated as stochastic and calculated through principal component analysis. Pirrong and Jermakyan (2008) also propose to model the equilibrium price as a function of two state variables. The state variables are given by electricity demand and

\footnotetext{
${ }^{1}$ Papers as Allaz and Villa (1993), Newbery (1998), Green (1999) and Bushnell (2007) using Cournot or supply function equilibria (SFE) framework observe the importance of forward contracts to reduce market power. On the other hand, Ferreira (2003), Mahenc and Salanie (2004), Liski and Montero (2006) and Green and Le Coq (2006) find opposite results using Bertrand models or focusing on the dynamic aspects of contracts.
} 
the futures price of the marginal fuel, where electricity prices are an increasing function of demand. Cartea and Villaplana (2008) use an exponential function of two observable state variables: demand and generation capacity. They assume that electricity prices are increasing in demand and decreasing in capacity and propose a closed-form pricing model for forward prices taking into account seasonality and heteroskedasticity. Lyle and Elliott (2009) build on Cartea and Villaplana's model and use more sophisticated supply assumptions. They also improve the estimation procedures and derive a closed form solution for European option prices written on average spot prices.

All the aforementioned models implicitly assume competitive markets and a pay-as-bid pricing mechanism without explaining if it is a good approximation for markets with more complex structures. None of these derivative models address central aspects of many wholesale electricity markets: market power, vertical integration, contracts and a uniform price auction design. This paper addresses how more realistic market structure can affect hybrid pricing modeling.

To evaluate the bidding behavior of generators, Hortacsu and Puller(2005, 2008) develop a one-period equilibrium model that deals with electricity spot price formation in markets characterized by oligopoly and uniform price auction design. $^{2}$ We adapt their model to take into account demand and supply shifters and to allow for vertical integration. The result is a theoretically well founded linear relationship between spot price and state variables. We then apply the Lucia and Schwartz (2002) two factor arbitrage pricing results along with our spot price formation model to calculate a closed form solution for forward/future prices. We evaluate how hedge prices are affected by the market structure and the dynamics of state variables. Most importantly, we show how spot market power affects the hedge market. We also use our forward pricing model to analyze the New Zealand Electricity Market (NZEM).

The paper is organized as follows. Section 2 presents and discusses our equilibrium spot price model. Section 3 presents our hybrid pricing application to evaluate forward prices and the role of spot market power. Section 4 exhibits an empirical exercise where the NZEM is analyzed.

\section{Spot Price Model}

\subsection{Assumptions}

Consider the following structure. The wholesale market is oligopolistic and firms can be vertically integrated (such firms are commonly referred to as "gentailers"). The electricity market has $N$ total players made of $K$ generators, $R$

\footnotetext{
${ }^{2}$ Their model produces a theoretical ex-post optimal result. We consider reasonable to assume that players behave optimally for our hybrid pricing purposes. The authors concentrate, however, on the empirical task of comparing the actual bidding behavior in the texan (ERCOT) electricity market to their theoretical benchmark. Their empirical finds that big generators (relevant participation in the market) perform closely to their theoretical model seems to reinforce our choice.
} 
retailers and $I$ gentailers. The wholesale spot price at a given time is determined through a uniform price auction, where generators submit an individual supply schedule and an auctioneer clears the market. Aggregate consumer's demand and generators' cost functions are influenced by a given set of state variables assumed as known at the moment of the auction. State variables drive the stochastic behavior of demand and supply through time. A retailer's revenue is determined by an exogenous retail price and each retailer's market share of aggregate consumer demand. The only source of uncertainty at the time of the auction for a given generator is the rival's electricity contract positions and respective prices. Both the contract positions and prices are considered as exogenous. All these assumptions will now be formalized and motivated.

Definition 2.1. State variables are represented by the L-dimension state variables vector $\vec{W}_{t}=\left\{w_{1 t}, w_{2 t}, \ldots, w_{L t}\right\}$ which is assumed to be exogenous and known by all firms at time $t$.

Here we define consumer demand and generator cost shifters. These shifters are assumed as known at time $t$. They are responsible for the stochastic behavior of price through time. in other words, players are assumed to make their decision and the market equilibrium is set given all the information available at $t$.

Definition 2.2. The consumers' aggregate demand at time $t$ is defined by the function $\tilde{D}_{t}=D_{t}\left(p_{t}^{R}, \vec{W}_{t}\right)$. Retail price $p_{t}^{R}$ is assumed to be exogenous.

Aggregate demand is only affected by the state variables $\vec{W}_{t}$ and the retail price $p_{t}^{R}$. At the time of the auction, the demand function is deterministic. This definition is equivalent to assuming that instantaneous demand shocks are negligible. Uniform-price auctions used to clear electricity spot markets have a very short-term horizon. Bids into uniform price electricity auctions are made for delivering energy close to dispatch. In markets such as the NZEM, the bid can be modified until two hours to the delivery time. The more significant source of uncertainty for a specific bidder at the time of the auction is the hedging position of his rivals.

Frequently, the literature considers the state variable as the observed demand itself $D_{t}=w_{1 t}$. However, we can also think in terms of demand shifters such as income, economic activity, institutional changes, seasonality or climate factors. The assumption of exogeneity of $p_{t}^{R}$ is a good approximation for electricity markets for two reasons. First, retail prices are frequently regulated. Second, even when retail prices are freely determined, contracts between retailers and customers usually have a long-term nature. In other words, it is not reasonable to assume that retailers react to each instantaneous oscillation in the spot market when deciding the price they charge consumers. ${ }^{3}$

Definition 2.3. Retailers' demand (gentailer or pure retailer) is defined as $m_{i} \tilde{D}_{t}\left(p_{t}^{R}, \vec{W}_{t}\right), \forall i=1,2, \ldots, R$. Here $m_{i}>0$ is the given market share of

\footnotetext{
${ }^{3}$ In reality, wholesale and retail demand can can present different features. In fact retail and industrial prices are frequently not the same. However, to keep the model simple, we consider just one aggregate demand affected by retail prices.
} 
retailer $i$ and $\sum_{i=1}^{R} m_{i}=1$, since gentailers are included in retailers. By construction, $\sum_{i=1}^{R} m_{i} \tilde{D}_{t}\left(p_{t}^{R}, \vec{W}_{t}\right)=\tilde{D}_{t}\left(p_{t}^{R}, \vec{W}_{t}\right)$.

A retailer's demand is assumed to be a fixed proportion of the total consumers' demand and, by construction, the total retailers' demand must be equal to the aggregate consumers' demand. The exogeneity of $m_{i}$ reflects the idea that the retail market shares are relatively fixed. It is certainly reasonable to assume that at the moment of an auction the retail market share is known and exogenous. In reality, contract arrangements between retailers and final consumers are relatively stable in comparison to the strong variations observed in both demand and generation inputs. Therefore, this assumption is a good approximation for the short or medium-term.

Definition 2.4. $Q C_{i t}$ is firm $i$ 's contracted quantity of electricity to deliver (buy if negative) at time $t$, for all $i=1,2, \ldots, N . P C_{i t}$ refers to the price paid for these contracts.

Definition 2.5. The other firms' correspondences $\left(Q C_{j t}, P C_{j t}\right) \forall j \neq i$ are unknown by firm $i$.

The quantity $Q C_{i t}$ is defined as the total amount of electricity that firm $i$ is forward contracted to deliver (or to buy if negative) at time $t$. $Q C_{i t}$ represents firm $i$ 's portfolio of forward contracts maturing at $t$, negotiated at different times in the past. In this case, price $P C_{i t}$ would be a weighted average forward price of this portfolio.

Forward contracts constitute an important part of competitive electricity wholesale markets. Wholesalers, retailers and gentailers frequently manage their spot price risk trading significant amounts of forward contracts of different maturities in over the counter (OTC) markets. Because of the bilateral nature of OTC markets, market information is rarely available even for participants. Firms are often unaware of rivals' contract positions at a particular point in time. On the other hand, electricity markets are often characterized by a lack of relevant and liquid future exchanges. Therefore, existence of non marked-to-market forward prices and absence of information about rivals' average forward prices are very common features in electricity markets. Frequently, firms' forward positions at a particular time correspond to a complex portfolio, characterized by overlapping contracts established at different periods and prices.

Definition 2.6. Function $S_{i t}\left(p, Q C_{i t}, \vec{W}_{t}\right)$ represents generator $i$ 's supply for all $i=1, \ldots, K$. Define $S_{t}=\sum_{i=1}^{K} S_{i t}$ as the aggregate supply.

Definition 2.7. The total cost of each generator $i$ in time $t$, for all $i=$ $1,2 \ldots, K$, is $C_{i t}$ which is a function $C_{i t}\left(S_{i t}, \vec{W}_{t}\right)$ of the firm supply $S_{i t}$ and the vector $\vec{W}_{t}$. The marginal cost $M C_{i t}\left(S_{i t}, \vec{W}_{t}\right)$ is the partial derivative of $C_{i t}$ with respect to $S_{i t}$. Also, $C_{i t}$ is twice continuously differentiable and $\frac{\partial M C_{i t}}{\partial S_{i t}} \geq 0$.

We assume that generators have a well behaved cost function shifted by exogenous state variables. This assumption addresses the potential impact of 
cost shifters (e.g. capacity availability, temperature, precipitation and prices, or shadow prices, of inputs such as gas, fuel or water) in the marginal costs of the generators.

Definition 2.8. The market clearing wholesale price $p_{t}^{c}$ must equate aggregate demand and aggregate supply. $\sum_{i=1}^{K} S_{i t}\left(p_{t}^{c}, Q C_{i t}, \vec{W}_{t}\right)=\tilde{D}_{t}\left(p_{t}^{R}, \vec{W}_{t}\right)$

Firms simultaneously submit continuous supply schedules $\hat{S_{i t}}{ }^{4}$. Considering each firm's bid, the auctioneer computes the equilibrium price $p_{t}^{c}$ that satisfies the market clearing condition. Therefore, at the moment of the auction, from the perspective of firm $i$, the uncertainty in price is due to the uncertainty about the contract positions of rival firms and their respective prices $\left\{Q C_{j t}, P C_{j t}, j=\right.$ $1 \ldots N, j \neq i\}$.

Definition 2.9. Gentailer $i$ 's ex-post profit upon the realization of the market clearing price is (where $m_{i}=0$ for pure generators and $m_{i}>0$ for gentailers):

$$
\begin{aligned}
\pi_{i t}= & S_{i t}\left(p_{t}^{c}, Q C_{i t}, \vec{W}_{t}\right) p_{t}^{c}-C_{i t}\left(S_{i t}\left(p_{t}^{c}, Q C_{i t}, \vec{W}_{t}\right), \vec{W}_{t}\right) \\
& +m_{i}\left(p_{t}^{R}-p_{t}^{c}\right) \tilde{D}_{t}\left(p_{t}^{R}, \vec{W}_{t}\right)+\left(P C_{i t}-p_{t}^{c}\right) Q C_{i t}
\end{aligned}
$$

There are three possible sources of payoff for electricity companies $i=$ $1 \ldots N$ : operating profit from generation activity $\left(S_{i t}-C_{i t}\right)$, operating profit from retail activity $m_{i}\left(p_{t}^{R}-p_{t}^{c}\right) \tilde{D}_{t}$ and financial revenue $\left(P C_{i t}-p_{t}^{c}\right) Q C_{i t}$ from forward market transactions. ${ }^{5}$ As defined before, gentailers are characterized by participating in both generation and retail markets. Therefore, they have operating profits (or losses if negative) in both activities.

Definition 2.10. Pure retailer $i$ 's ex-post profit upon the realization of market clearing price is:

$$
\pi_{i t}=m_{i}\left(p_{t}^{R}-p_{t}^{c}\right) \tilde{D}_{t}\left(p_{t}^{R}, \vec{W}_{t}\right)-\left(p_{t}^{c}-P C_{i t}\right) Q C_{i t}
$$

\footnotetext{
${ }^{4}$ The fact that supply bids are assumed as such continuous functions simplifies the results. This assumption is adopted as a theoretical benchmark in Hortacsu and Puller (2008) and in the large Supply Function Equilibrium literature originated from Klemperer and Meyer (1989). In reality, however, bids are discrete. Papers such as Von der Fehr and Harbord (1993), and Kastl(2006, 2008) study the consequences of constrained bidding.

${ }^{5}$ Decentralized electricity industries are characterized by the coexistence of several overlapping markets. Electricity trading over any specific period of time can start from years to minutes before the actual delivery. Medium-term and long-term contracts are generally traded through forward and/or futures markets. They are usually financial markets in the sense that the delivery of electricity is optional and the seller's obligation is strictly financial (i.e. contracts are settled in cash). On the other hand, short-term transactions are made in the so called spot markets. In some competitive electricity industries, the definition of spot markets comprises both the day-ahead market and the real-time market. It is true that day-ahead markets increase market completeness and potentially raise short-term liquidity. However, despite their specific features, day-ahead markets are also financial markets. Similarly to forwards and futures, day-ahead trading is a straightforward negotiation in the sense that bid offers, quantities sold/delivered and prices are easily established. On the other hand, electricity real-time markets present unique features. First, they are the only physical markets (i.e. involves actual delivery of power). Second, they present issues and externalities that demand a close regulation by the system operator. For the purposes of this thesis, spot markets will be taken to mean the real-time markets exclusively.
} 
Notice that, as posed by definition 2.4, $Q C_{i t}$ may be negative. For example, if pure retailers solely buy electricity in the forward market, they have a negative contract position by our definition. Definition 2.10 assumes retailers as passive players in the instantaneous wholesale spot market. That is, a retailer's purchase is totally determined by his exogenous retail market participation $m_{i} \tilde{D}_{t}\left(P_{t}^{R}, W_{t}\right)$. It also means that there are no strategic alternatives considered by pure retailers and the spot market equilibrium is fully determined by supplier strategies and the exogenous aggregate demand. This is a reasonable approximation for most uniform-price auctions in electricity markets, where only suppliers bid and markets are cleared by an auctioneer responsible for matching supply curves to particular electricity demands.

Definition 2.11. The conditional cumulative distribution function of market clearing price $\left(p^{c}\right)$ realizations is:

$$
H_{i t}\left(p, \hat{S}_{i t}(p) ; Q C_{i t}, \vec{W}_{t}\right) \equiv \operatorname{Pr}\left(p_{t}^{c} \leq p \mid Q C_{i t}, \vec{W}_{t}, \hat{S}_{i t}(p)\right)
$$

where $\hat{S}_{i t}(p)$ is the supply schedule submitted by generator $i$ at time $t$.

As characterized by Wilson (1979) and explored by Hortacsu and Puller (2008), we can establish a Bayesian-Nash equilibrium by defining a probability measure over the realizations of the market clearing price from the perspective of generator $i$, conditional on generator $i$ 's private information about his contracts $\left(Q C_{i t}, P C_{i t}\right)$ and the fact that generator $i$ submits the supply schedule $\hat{S}_{i t}$ while its generation competitors are playing their equilibrium bidding strategies $\left\{S_{j t}\left(p, Q C_{j t}, \vec{W}_{t}\right), j=1 \ldots K, j \neq i\right\}$.

Lastly, we constrain the supply curves which firms may submit.

Definition 2.12. Demand curves bid by firms at time $t$ are bounded above in price by $\bar{p}_{t}$ and below by zero. Each firm is constrained in its maximum quantity which it can bid by $\bar{q}_{i t}$.

This assumption ensures existence of an expected profit maximising supply curve. Throughout the following analysis, we assume that:

Definition 2.13. $\bar{q}_{i t}$ is sufficiently large that any individual firm could supply the entire market demand single-handedly, and $\bar{p}_{t}$ is sufficiently large that any firm would be willing to meet the entire demand at this price.

This ensures that our requirement that demand curves be bounded does not materially impact supply decisions by firms. Even in the presence of time varying demand (Definition 2.2) the market auctioneer can choose $\bar{q}_{i t}$ and $\bar{p}_{t}$ to satisfy this condition.

\subsection{Equilibrium results}

Assume that generator/gentailer $i$ 's bidder when deciding the bid schedule $\hat{S}_{i t}(p)$ has utility maximizing behavior. The bidder $i$ expected utility maximization problem is: 


$$
\begin{gathered}
\max _{\hat{S}_{i t}(p)} \int_{0}^{\bar{p}} \quad\left[\hat{S}_{i t}(p) p-C_{i t}\left(\hat{S}_{i t}(p), \vec{W}_{t}\right)+m_{i}\left(p_{t}^{R}-p\right) \tilde{D}_{t}\left(p^{R}, \vec{W}_{t}\right)\right. \\
\left.\quad+\left(P C_{i t}-p\right) Q C_{i t}\right] d H_{i t}\left(p, \hat{S}_{i t}(p) ; Q C_{i t}\right),
\end{gathered}
$$

The integral is taken over all possible realizations of the market clearing price $\left(\varepsilon_{t}, Q C_{j t} ; Q C_{i t}, \vec{W}_{t}\right)$, for all $j \neq i$, weighted by the probability density $d H\left(p, S_{i t}^{*}(p) ; Q C_{i t}, \vec{W}_{t}\right)$. In other words, by offering to supply at a lower price, the bidder increases the likelihood that he will supply a larger quantity; whereas, by offering to supply at a higher price, the bidder increases the likelihood that he will supply a smaller quantity but at a higher price. Taking into account the inherent probability distribution of the clearing price and his own risk aversion, a rational bidder optimizes this tradeoff to maximize his expected profit.

Lemma 2.1. In equilibrium, assuming that supply schedules are continuously differentiable and that $S_{i t}^{*}(p)$ is the optimal supply curve of firm $i$ at time $t$, the first order condition of the bidder's (gentailer/generator) maximization problem is:

$$
p-M C_{i t}\left(S_{i t}^{*}(p), \vec{W}_{t}\right)=\left[S_{i t}^{*}(p)-Q C_{i t}^{*}-m_{i} D_{i t}\left(p_{t}^{R}, \vec{W}_{t}\right)\right] \frac{H_{S}\left(p, S_{i t}^{*}(p) ; Q C_{i t}^{*}\right)}{H_{p}\left(p, S_{i t}^{*}(p) ; Q C_{i t}^{*}\right)}
$$

Where

$$
\begin{aligned}
H_{p}\left(p, S_{i t}^{*}(p) ; Q C_{i t}^{*}\right) & =\frac{\partial}{\partial p} \operatorname{Pr}\left(p_{t}^{c} \leq p \mid Q C_{i t}^{*}, S_{i t}^{*}(p)\right) \\
H_{S}\left(p, S_{i t}^{*}(p) ; Q C_{i t}^{*}\right) & =\frac{\partial}{\partial S} \operatorname{Pr}\left(p_{t}^{c} \leq p \mid Q C_{i t}^{*}, S_{i t}^{*}(p)\right)
\end{aligned}
$$

Proof: appendix A.

This result follows from the deterministic nature of all non-control variables of the bidder's maximization problem at time $t$. The bidder's problem solution in every state of nature is attainable and produces a supply schedule that is a monotonically increasing function of price. In other words, the bidder chooses an optimal supply for each state of nature given by his rivals' forward contracts.

As pointed out by Hortacsu and Puller (2008), $H_{p}$ is the 'density' of the market clearing price when firm $i$ bids $S_{i t}^{*}(p)$. The derivative $H_{S}$ captures the market power of $i$ and can be interpreted as the 'shift' in the probability distribution of the market clearing price, due to a change in $S_{i t}^{*}(p)$. This derivative is always nonnegative, because an increase in supply weakly lowers the market clearing price, which weakly increases the probability that the market clearing price is lower than a given price $p$.

This formula is consistent with market power or, in other words, the existence of declining residual demand curves. Each bidder is independently selecting his 
bid to maximize profits based on his estimate of the residual demand curve he faces. Equation (4) also implies that the existence of either forward contracts or vertical integration mitigates the market power of electricity producers. Observe, however, that for a competitive market we have $p=M C$ independently of the quantity contracted by the generators $\left(\right.$ as $\left.H_{S}=0\right)$.

Equation (4) raises three complications. First, as observed by Hortacsu and Puller (2008), its empirical implementation requires the estimation of $H_{i t}$ for each bidder $i$, in every period $t$ which is a complex econometric problem. Second, the computation of equilibrium strategies is a complicated task because $H_{i t}$ is determined endogenously through the market clearing condition and depends on the joint distribution of contract positions. ${ }^{6}$ Third, without further assumptions, equation (4) is prone to multiple equilibria. Anderson and Philpott (2002) point out that this is a particularly relevant problem to supply function equilibrium models (SFE) when demand is assumed to be inelastic to wholesale prices (definition 2.2). ${ }^{7}$

However, as shown by Hortacsu and Puller (2008), the characterization of equilibrium strategies is greatly simplified when the functional form of the firm $i$ supply strategy is additively separable in price $p$ and quantity contracted $Q C_{i}$, in which case changes in exogenous variables such as $Q C$ or $\vec{W}$ shift the equilibrium supply strategies but do not rotate them. Notice, however, that exogenous variables can change suppliers' price elasticities despite not affecting the suppliers' price derivatives. We show that the same assertion is also valid in our framework.

An important caveat, as noticed by Hortacsu and Puller (2008), is that the additive separability is an a priori restriction on bidding strategy. It is not necessarily true that every specification of marginal cost functions and joint distribution of contract quantities will lead to equilibrium strategies of this form. However, the authors test the additive separability assumption for the Ercot market and find that the restriction holds on average across bidders.

Lemma 2.2. At any time, suppose supply function strategies $S_{i}\left(p, Q C_{i}, \vec{W}\right)$ are restricted to the additively separable class of strategies:

$$
S_{i}\left(p, Q C_{i}, \vec{W}\right)=\alpha_{i}(p)+\beta_{i}\left(Q C_{i}\right)+\sum_{l=1}^{L} \delta_{l i}\left(w_{l i}\right)
$$

then for a range of prices $p \in[0, \bar{p}]$ the first order condition at time $t$ turns to:

$$
p_{t}-M C_{i t}=\frac{S_{i t}-Q C_{i t}^{*}-m_{i} D_{t}}{\frac{\partial \sum_{j \neq i} S_{j t}}{\partial p_{t}}}
$$

\footnotetext{
${ }^{6}$ See Hortacsu and Puller (2008) pages 93 and 94.

${ }^{7}$ The SFE approach was originally developed by Klemperer and Meyer (1989) and first applied to the electricity market by Green and Newbery (1992) and Bolle (1992). Holmberg and Newbery (2010) offer a broad review on the SFE literature and show that when there are non-linear strategies considered, there could be other equilibria.
} 
Alternatively,

$$
\frac{p_{t}-M C_{i t}}{p_{t}}=\frac{1}{\varepsilon_{i t}^{\prime}\left(q_{i t}^{\prime}\right)}
$$

Where $\varepsilon_{i t}^{\prime}\left(q_{i t}^{\prime}\right)$ is the elasticity of the net residual demand $q_{i t}^{\prime}$, here defined as $q_{i t}^{\prime}=D_{t}-\sum_{j \neq i} S_{j t}-Q C_{i t}^{*}-m_{i} D_{t}$.

Proof: appendix B.

As posed by Holmberg and Newbery (2010), mark-ups in the real-time market only influence the revenue from sales net of forward contracting. It is the residual demand net of forward contracts that are relevant for a profit maximizing producer. The first order condition given by equation (6) states an analogous result. Taking into account vertical integration, if an equilibrium exists, it is the residual demand net of forward contracts and retail sales that matters.

A producer offers positive net-supply with positive mark-ups in the realtime market. If a producer has negative net-supply, i.e. he has to buy back electricity in the real-time market, then he will use his market-power to push down the price. Hence mark-ups are negative for negative net-supply. Mark-ups are zero at the contracting point where net-supply is zero. Therefore, the existence of forward contracts and vertical integration mitigates incentives to bid above marginal costs.

Specifically, a necessary condition for equilibrium is that firm $i$ 's supply $S_{i}$ is such that his Lerner index $\frac{p_{t}-M C_{i t}}{p_{t}}$ corresponds to the inverse of the elasticity $\frac{1}{\varepsilon_{i t}\left(q_{i}\right)}$ of his residual demand $D_{t}-\sum_{j \neq i} S_{j t}$ net of his equilibrium forward position $Q C_{i t}^{*}$ and his participation in the retail market $m_{i} D_{t}$. In other words, the elasticity of the net demand $q_{i}$ fully explains wholesaler $i$ 's market power. This result comes though from the additional assumption of instantaneous perfect inelasticity of aggregate demand $D_{t}$ to wholesale spot prices $p_{t}$ at time $t$.

Proposition 2.3. If (i) there are a fixed number $K>2$ generators/gentailers in the market, (ii) marginal cost functions are linear and symmetrical between firms in the market $\left(M C_{i t}\left(S_{i t}, \vec{W}_{t}\right)=a+b S_{i t}+\sum_{j=1}^{L} \rho_{j} w_{j t} \forall i=1,2, \ldots N\right.$, where $b>0$ ) and (iii) the aggregate demand is linear with constant retail price $\left(D_{t}\left(p_{t}^{R}, \vec{W}_{t}\right)=c-\kappa_{o} p^{R}+\sum_{j=1}^{L} \kappa_{j} w_{j t}\right)$ then there is a unique equilibrium where the optimal supply and the clearing wholesale spot price can be rewritten are the following:

$$
\begin{aligned}
S_{i t}^{*}= & -\frac{a(K-2)}{b(K-1)}+\frac{K-2}{b(K-1)} p_{t}+\frac{1}{K-1} Q C_{i t} \\
& +\frac{m_{i}}{K-1} D_{t}\left(p_{t}^{R}, \vec{W}_{t}\right)-\frac{(K-2)}{b(K-1)} \sum_{j=1}^{L} \rho_{j} w_{j t} \\
p_{t}^{c} & =A-B \sum_{i=1}^{K} Q C_{i t}^{*}+\sum_{j=1}^{L} C_{j} w_{j t}
\end{aligned}
$$


Where

$$
\begin{aligned}
A & =a+b \frac{\left(c-\kappa_{o} p^{R}\right)\left(K-\left(1+\sum_{i=1}^{K} m_{i}\right)\right)}{K(K-2)} \\
B & =\frac{b}{K(K-2)} \\
C_{j} & =\rho_{j}+b \frac{\left(K-\left(1+\sum_{i=1}^{K} m_{i}\right)\right)}{K(K-2)} \kappa_{j}
\end{aligned}
$$

Proof: appendix C.

Equation (8) shows that positive shifts in generators' costs and in aggregate demand increase the spot price. An increase in the retail price decreases spot price. The sum of generators' contracts $\sum_{i=1}^{K} Q C_{i t}$, play an important role in price formation. ${ }^{8}$

Equation (8) also shows that, holding forward contracts constant, an increase in the degree of vertical integration $\left(\sum_{i=1}^{K} m_{i}\right)$ in the market implies a decrease in spot prices. The reason is that more vertically integrated firms have a smaller net supply $S_{i t}-m_{i} D_{i t}$ and therefore less incentives to exert market power in the wholesale market taking contracts as fixed. ${ }^{9}$

Corollary 2.4. If $K \rightarrow \infty$ then $p \rightarrow M C$.

There are two exceptions where the hedging decision does not matter for spot price modeling purposes, notwithstanding the size of the electricity hedging market. The first, as posed by the corollary above, refers to the perfect competition case. If the number of generators in the market goes to infinity, the mark-up component of the spot price tends to zero. In the limit, we have the competitive result of spot price being equal to generators' marginal cost. In other words, if generators in an electricity market were atomized, wholesale prices would be primarily driven by their marginal costs. In practice, perfect competition does not exist in electricity wholesale markets.

\footnotetext{
${ }^{8}$ The aggregate position of generators $\left(\sum_{i=1}^{K} Q C_{i t}\right)$ is close to zero and does not affect spot prices in two basic situations: (i) electricity markets with a poorly developed forward market and (ii) fully vertically integrated markets as defined later in this paper. In particular, markets made exclusively of gentailers with the same market share in both the retail and generation markets have little reason to develop forward markets on a large scale, since their wholesale transactions are internally hedged.

${ }^{9}$ Hogan (2010) finds a similar result in a different and deterministic framework, addressing the incentives of gentailers and pure retailers. He finds that the vertically integrated firm has an incentive to compete more aggressively in the retail market than pure retailers. Gans, Wolak, and Carlton (2008) find opposite results considering the role of passive vertical integration. They find that an increase in vertical integration would decrease quantity contracted that would in turn increase spot prices. This result relies strongly that the wholesale and retail businesses are completely separated (independent). This means that the gentailers do not necessarily make a first best decision. Specifically, the forward contract aspects of vertical integration are not considered in the gentailers' supply decision.
} 
Corollary 2.5. If $K=N$ then $\sum_{i=1}^{K} m_{i}=\sum_{i=1}^{N} m_{i}=1$ and we have:

$$
p_{t}^{c}=a+\frac{b c-\kappa_{o} p^{R}}{K}+\sum_{j=1}^{L}\left(\frac{b}{K} \kappa_{j}+\rho_{j}\right) w_{j t}
$$

The second concerns the case where forward contracts are fully cleared by generators $\left(\sum_{i=1}^{K} Q C_{i t}=0\right)$. From equation (9), this fact applies to markets where $K=N$. That is, where all the firms in the market are generators or gentailers (i.e. all retailers are also generators). In such a case, contracts do not affect the aggregate supply and, consequently, the clearing spot price.

Since this model approximates demand and marginal costs by linear functions, by equation (7) the optimal individual supplies are also linear. In particular, they are positively affected by the quantity contracted $\left(Q C_{i t}\right)$. Gentailers can be net wholesalers, net retailers or have the same share in both markets. Intuitively, in order to hedge risks, they are expected to have $Q C_{i t}>0, Q C_{i t}<0$ and $Q C_{i t}=0$ respectively. Therefore, if all the players are gentailers and the aggregate supply is linearly affected by the sum of the generators' outstanding contracts, it is reasonable to expect that the oversupply of net wholesalers will offset the undersupply of net retailers and the aggregate outstanding contracts will have no effect on the aggregate demand.

Define markets where $K=N$ as fully vertically integrated markets. Notice that this definition is broader than the usual definition of full vertical integration in the literature, as it admits mismatch between the participation of an individual gentailer in the generation and retail markets. ${ }^{10}$ Our definition comprises (but it is not limited to) either (i) markets where all the generators are gentailers $(K=I=N)$ or, more strictly, (ii) markets where each generator sells all his production directly to consumers through his retail business (individual full vertical integration).

The gentailer dominated electricity markets of Spain, New Zealand or Germany, for example, fit closely to this definition. In New Zealand, the market is dominated by gentailers but some firms present mismatch between their wholesale and retail market shares. In other words, there are big net wholesalers and big net retailers.

Notice that the clearing price is equal to the average marginal cost in fully vertically integrated electricity markets since, in equilibrium, the average supply $\bar{S}$ is equal to the aggregate demand divided by the number of gentailers $\left(\bar{S}=\frac{D}{K}\right)$. This means that individual firms may have market power when $K=N$ but the average mark-up in the market is equal to zero. Equation (9) is used in the empirical exercise of session 4.

\section{Dynamics and Forward prices}

A large portion of the energy traded in most competitive electricity markets is hedged. Forward and futures contracts frequently constitute the most significant

\footnotetext{
${ }^{10}$ As for example Dixit (1983).
} 
hedging instruments. This section provides a closed-form solution to evaluate how concentration in the electricity generation industry impacts the forward price curve.

Suppose we have two relevant state variables in the market: the aggregate demand and the generators' marginal cost shifter. We assume that for hydrodominated markets like New Zealand, a good proxy for the cost shifter is the shadow price of water. Increases in this price represent changes in the scarcity of water in the reservoir and affect firms' marginal costs positively. Aggregate demand follows a stochastic process mean reverting towards a deterministic function of time. This function can be used to describe, for example, seasonal patterns. The shadow price of water follows a simple arithmetic Brownian motion. Interest rates are assumed constant in what follows. Under this assumption, forward and future prices are equal. Formally, we have the following spot market setting:

$$
\begin{aligned}
D_{t}\left(p_{t}^{R}, \vec{W}_{t}\right) & =w_{1 t} \\
M C_{i t}\left(S_{i t}, \vec{W}_{t}\right) & =a+b S_{i t}+\rho w_{2 t} \quad \forall i=1,2, \ldots, K
\end{aligned}
$$

Demand is fully explained by the state variable $w_{1 t}$. State variable $w_{2 t}$ represents the shadow price of water. The parameter $\rho$ reflects how sensitive to changes in $w_{2 t}$ the marginal cost is. In the notation of proposition 2.3 , we have $c=\kappa_{o}=0$ (perfectly inelastic demand) and $\kappa_{1}=1$. Define $M=\sum_{i=1}^{K} m_{i}$ and assume that the aggregate net position of generators and gentailers is approximately constant $\left(Q C=\sum_{i=1}^{K} Q C_{i t}^{*} \forall t\right)$. Then, by rearranging equation (8), the spot price formation equation becomes:

$$
p_{t}=a-\frac{b Q C}{K(K-2)}+\frac{b(K-1-M)}{K(K-2)} w_{1 t}+\rho w_{2 t}
$$

Regarding the state variable dynamics, we assume:

$$
\begin{aligned}
w_{1 t} & =f(t)+x_{1 t} \\
d x_{1 t} & =-\psi x_{1 t} d t+\sigma_{1} d Z_{1} \\
d w_{2 t} & =\mu d t+\sigma_{2} d Z_{2} \\
d Z_{1} d Z_{2} & =\phi d t
\end{aligned}
$$

The aggregate demand $w_{1 t}$ has two components. The first is a completely predictable function of time $f(t)$ which can incorporate seasonality. The second is a diffusion stochastic process $\left(x_{1 t}\right)$. Particularly, $x_{1 t}$ follows a stationary mean-reverting process, or Ornstein-Uhlenbeck process, with a zero long-run mean where the speed of adjustment is $\psi>0$, the volatility is $\sigma_{1}$, and $d Z_{1}$ represents an increment to a standard Brownian motion. The shadow price of water $w_{2 t}$ follows an arithmetic Brownian motion with drift $\mu$ and volatility $\sigma_{2}$ ( $Z_{2}$ is a standard Brownian motion). The state variables are correlated through equation (16). The correlation between $Z_{1}$ and $Z_{2}$ is given by $\phi$. The idea is to keep the model simple to infer how the market parameters affect forward prices in an arbitrage pricing setup. 
Proposition 3.1. Assume the spot price stochastic behavior described by equations (12-16). We have the following formula for the forward prices PC at $t$ for electricity delivered at time $T$ :

$$
\begin{aligned}
P C\left(p_{t}, T\right)= & a-\frac{b Q C}{K(K-2)}+\frac{b(K-1-M)}{K(K-2)}\left(f(T)+e^{-\frac{\psi b(K-1-M)}{K(K-2)}(T-t)} x_{1 t}\right) \\
& +\rho w_{2 t}+\left(1-e^{-\frac{\psi b(K-1-M)}{K(K-2)}(T-t)}\right) \eta^{*}+\mu^{*}(T-t) \\
\eta^{*}= & -\lambda_{1} \sigma_{1} / \psi \\
\mu^{*}= & \rho\left(\mu-\lambda_{2} \sigma_{2}\right)
\end{aligned}
$$

Where $\lambda_{1}$ and $\lambda_{2}$ are the market prices of risk for demand and for the shadow price of water respectively. Proof: Lucia and Schwartz (2002).

Equations (17) explain how $P C$ is affected by the parameters associated with the spot price formation and the state variables in this closed formula.

Corollary 3.2. Assume $a \geq 0, b \geq 0, \rho \geq 0, Q C \geq 0, \mu \geq 0, \psi \geq 0$ and $f(T) \geq 0 \forall T$. From equation (17) we have the following: $\frac{\partial P C}{\partial a} \geq 0, \frac{\partial P C}{\partial x_{1 t}} \geq 0$, $\frac{\partial P C}{\partial w_{2 t}} \geq 0, \frac{\partial P C}{\partial \mu} \geq 0, \frac{\partial P C}{\partial \sigma_{1}} \leq 0, \frac{\partial P C}{\partial \lambda_{1}} \leq 0, \frac{\partial P C}{\partial \sigma_{2}} \leq 0, \frac{\partial P C}{\partial \lambda_{2}} \leq 0$ and $\frac{\partial P C}{\partial Q C} \leq 0$. Proof: appendix D.

Under the assumptions of Corollary 3.2 several results arise. Increases in the fixed portion of the marginal cost $(a)$ affect forward prices positively. Ignoring seasonality issues given by $f(T)$, increases in the current level of demand $\left(x_{1 t}\right)$ and shadow price of water $\left(w_{2 t}\right)$ also increase forward prices. Last, ceteris paribus, increases in the exogenous aggregate quantity contracted by generators $Q C$ decreases forward prices.

Regarding dynamics, raising the water price long-term drift $\mu$ augments $P C$. Positive shifts in demand risk $\left(\sigma_{1}\right)$ and/or price of risk $\left(\lambda_{1}\right)$ as well as in water risk $\left(\sigma_{2}\right)$ and/or price of risk $\left(\lambda_{2}\right)$ shift forward prices downwards. That is, an increase in both market prices of risk and cost and demand volatilities decreases forward prices. If the uncertainty is high or expensive, generators accept a smaller price for the same amount of electricity delivered in the future.

On the other hand, increases in the speed of aggregate demand's mean reversion $(\psi)$, in the sensitivity of marginal costs to the shadow price of water $(\rho)$ or in the maturity $(T)$ have an ambiguous effect on $P C$. The impact of $K$ and $b$ on forward prices is also ambiguous. For example, a decrease in $K$ (increase in $b$ ) magnifies the negative effect of the outstanding quantity contracted on forward prices at the same time that it accentuates the positive impact of the demand. The net effect depends on the relationship between variables and parameters such as $K, \psi, b, T, x_{1 t}, f(T), M$ and $Q C$. We use arbitrary parameters to show, through an illustrative example, that market power in the spot market and forward prices are possibly connected. Assuming $f(T)=0$ and considering arbitrary parameters, Figure 1 illustrates the relationship between the number of generators/gentailers in the market and forward prices for different maturities. In particular, to stress the relationship between $K$, market power and 
Figure 1: Market power and forward prices as a function of contract maturity (parameters: $a=5, b=0.4, \rho=0.1, \psi=0.8, \sigma_{1}=10, \lambda_{1}=0.5, x_{1 t}=50$, $M=0.5, Q C=0, \mu=20, \sigma_{2}=5, \lambda_{2}=0.5$ and $\left.w_{2 t}=15\right)$

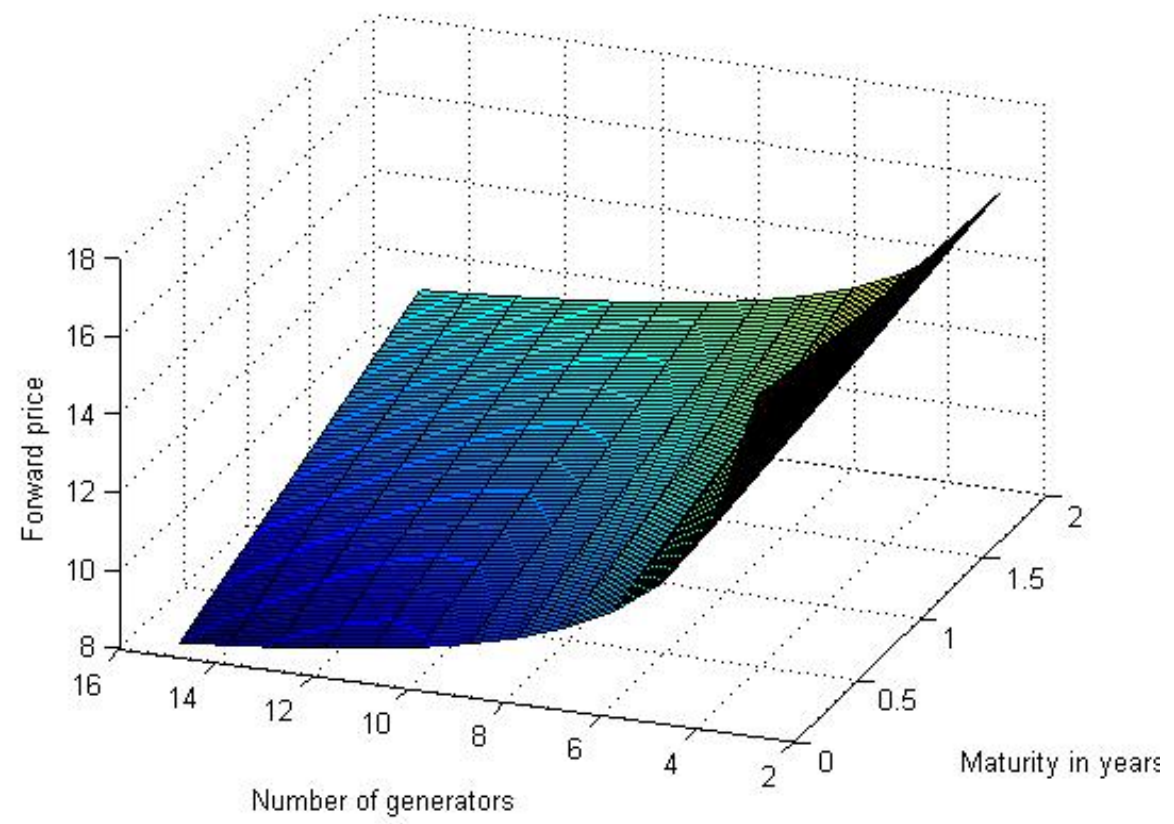

forward prices, this example first considers an electricity market with $Q C \approx 0$. That is, an electricity market where most of the forward contracts are cleared by generators and gentailers. Recall that a gentailers can be net retailers with a long position in the forward market $Q C_{i}<0$.

In this case, an increase in $K$ has two impacts on forward prices. It decreases the equilibrium spot price $p^{c}$ through a decrease in both the average marginal cost $\overline{M C}$ and the average price mark-up $\left(p^{c}-\overline{M C}\right)$. The first effect is directly related to the assumption of decreasing returns to scale given by the linear marginal cost function with $b>0$. That is, an increase in $K$ decreases the average scale of generators $\left(\frac{D}{K}\right)$, which decreases their average marginal cost (increases their average efficiency). The second effect is related to the average market power exerted by the generators since it affects the average Lerner index.

We observe from Figure 1 that positive changes in the number of generators $(K)$, which on average imply a more competitive environment and a more efficient production, reduce forward prices. In fact, an increase in $K$ not only shifts the forward curve downwards but can also rotate it. Thus, market concentration can have different implications along the forward curve. Particularly, the illustrative example shows a situation in which concentration plays a bigger 
role for shorter maturities. ${ }^{11}$

Figure 2: Market power and forward prices as a function of contract maturity (same parameters as Figure 1 with $b$ adjusting for a fixed marginal cost)

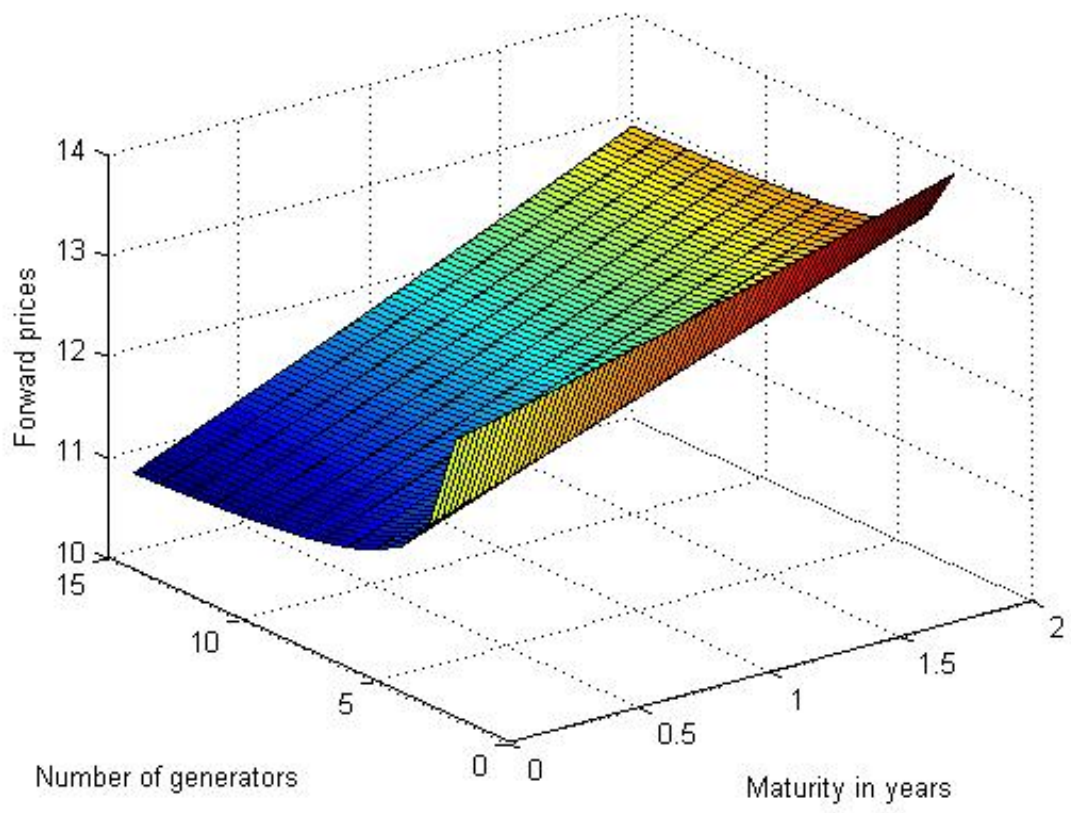

To isolate the market power effect, assume that $b$ adjusts in order to maintain the average marginal cost fixed. Given our assumptions, Figure 2 shows that an increase in market power also shifts the forward curve positively and rotates it in the same way as in the previous Figure. However, the magnitude of the impact of $K$ on the forward price $P C$ is reduced when controlled for its effect on the average $M C$.

Given our assumptions, the fact that forward prices can be higher in electricity markets with less generators is a particularly relevant result. It means that, contrary to results frequently observed in the literature, there is a possible situation where forward contracts, instead of reducing the spot market power, can be, in fact, affected by it (since $P C$ is potentially affected by market power). For example, Allaz and Villa (1993), Newbery (1998), Green (1999) and Bushnell (2007) observe the importance of existing forward contracts to reduce market power.

\footnotetext{
${ }^{11}$ Given the parameters assumed in Figure 1, an increase in $\rho$ or $T$, increases $P C$. For high values of $\sigma_{2}$ (e.g. $\left.\sigma_{2}=200\right)$, the effect has the opposite sign. On the other hand, The parameter $\psi$ has a negative effect on $P C$ in the example above. For a sufficient high value of $\sigma_{1}$ (e.g. $\left.\sigma_{1}=1000\right)$, an increase in $\psi$ augments $P C$.
} 
Figure 3: Market power and forward prices as a function of contract maturity (Same assumptions as Figure 2 except for $Q C=10$ )

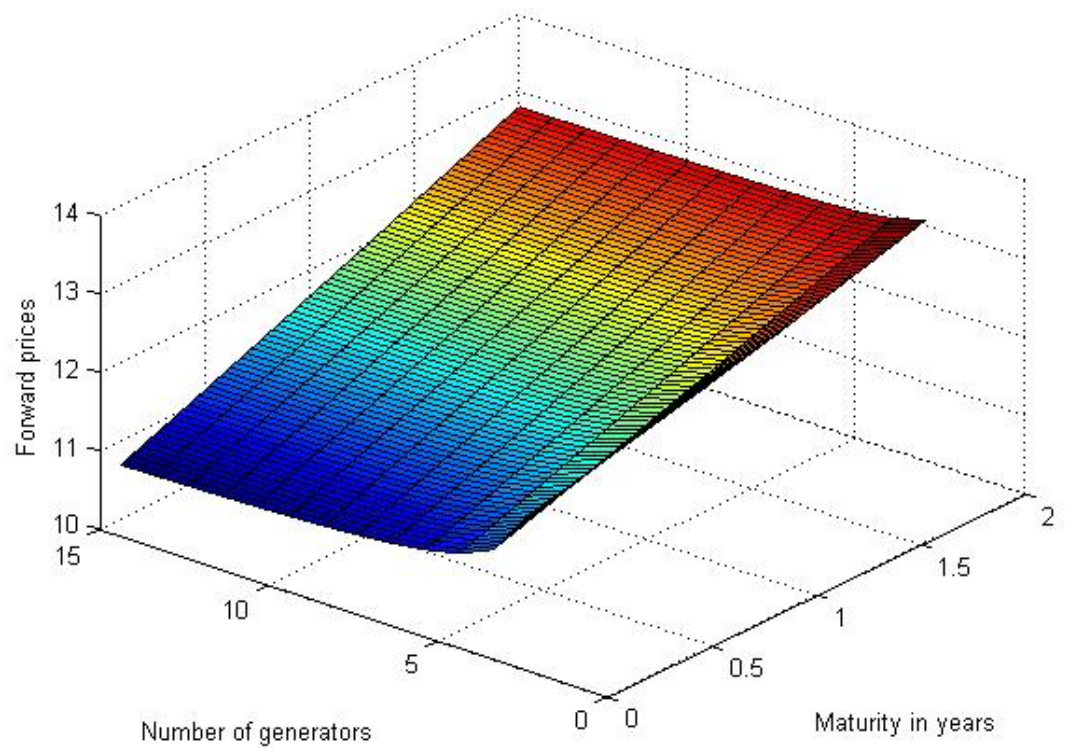

Figure 3 analyzes the effect of assuming $Q C=10$ (20\% of the assumed initial demand $x_{1 t}$ ). The other parameters are the same as used in Figure 2. It shows that there is still a positive, but smaller, effect of market power on the forward curve. This is reasonable, since an increase in $Q C$ decreases spot price mark-up as shown by equation (5).

This exercise shows that if the market becomes less concentrated the forward curve can be shifted or rotated. Specifically, generators' market power in the spot market can inflate forward prices and translate into market power in the hedge market. This analysis has let $K$ change given $Q C$ fixed.

\section{Empirical Exercise}

The objective of this section is to use our forward pricing model to analyze the New Zealand Electricity Market (NZEM). We adopt a two-step empirical strategy. The first step consists of estimating the spot price model parameters. The second step involves the implicit calibration of the market prices of risk $(\lambda$ 's) from the observed forward prices.

The reason for not estimating the spot price model and the market prices of risk jointly is that the forward price data is unbalanced and irregular. That is, we have days where several overlapping forward contracts are traded and days 
with no trade at all. Reconciling the spot price data with the forward price data available would imply losing relevant information about the spot market dynamics. Besides, the forward price formula is non-linear in several spot price model parameters which would unnecessarily complicate the empirical exercise.

The electricity spot market in New Zealand is characterized by a bid-based nodal market where half-hourly uniform-price auctions establish the spot prices for each relevant node of the system. NZEM also has an active forward market and potentially oligopolistic wholesalers. Table 1 shows that the NZEM has a

Table 1: Market Shares in NZ (2008)

\begin{tabular}{lcc}
\hline Company & Generation & Retail \\
\hline Contact Energy & $26 \%$ & $27 \%$ \\
Genesis Energy & $22 \%$ & $25 \%$ \\
Meridian Energy & $28 \%$ & $12 \%$ \\
Mighty River Power / Mercury Energy & $14 \%$ & $19 \%$ \\
Trust Power & $5 \%$ & $11 \%$ \\
\hline Total & $95 \%$ & $94 \%$ \\
\hline Source: Companies' annual reports 2008 and NZ Electricity Commission.
\end{tabular}

concentrated spot market with $K=5$ big players and presents a high degree of vertical integration. That is, the retail market share of generators is equal to $\left.M=\sum_{i=1}^{K} m_{i}=95 \%\right)$. Notice that it does not mean that the gentailers have the same market share in both the generation and retail markets. For example, Meridian Energy is a net generator with $28 \%$ of the generation market share and $12 \%$ of the retail market share and, on the other hand, Mercury Energy is a net retailer with $12 \%$ of the generation market and $19 \%$ of the retail market.

As an approximation, suppose that the assumptions of corollary 2.5 hold. That is, we assume that NZEM is fully vertically integrated $(K=N)$. This means that the market is predominantly composed of gentailers, that can be either net retailers such as Mercury Energy or net gentailers such as Meridian Energy. That is, individual firms are not necessarily fully vertically integrated. Under our equilibrium framework, markets with a very high degree of vertical integration (not necessarily of individual firms) have a clearing spot price which is not affected by forward contracts. Individual gentailers (net generators) in such markets can exert market power. However, by equation (5), the average spot price mark-up in equilibrium is equal to zero. ${ }^{12}$ The $K=N$ assumption also offers a simple linear relationship between electricity spot price and state variables, given by equation (9), which can easily incorporate dynamics.

The New Zealand electricity market is dominated by hydro power with significant participation of gas thermal generation. Therefore, the basic candidates for marginal cost shifters would be the prices of stored water and/or gas.

\footnotetext{
${ }^{12}$ For all $K>2$, equation (5) states that $E(p)-M C=0$ in situations where an individual gentailer is fully vertically integrated. Equation (5) also shows that, if gentailers own the entire retail market, the average mark-up equals zero even if individual firms are not fully vertically integrated.
} 
In particular, Evans, Guthrie, and $\mathrm{Lu}$ (2010), take into account the optimal intertemporal choices regarding electricity production and water storage and show that, once adjusted for transmission costs, the shadow price of water is the same as the shadow price of gas. ${ }^{13}$ However, shadow prices are by definition non-observable variables. ${ }^{14}$ The challenge is to find the best proxy or proxies for these generation inputs.

There are some primary candidates. The water inflow to the hydro system, for example, is clearly correlated with the shadow price of water. The storage option decreases in value when the inflows are abundant and increases when inflows are scarce. By similar reasons, past gas generation could also be used as a proxy for the shadow prices of stored gas. International gas or oil price indexes could be another possibility. All these alternatives present the same important drawback: they abstract from marginal valuations and are autocorrelated.

We first consider water inflows $\left(\mathrm{m}^{3} / \mathrm{s}\right)$ in the hydro system as the cost shifter $w_{2 t}$. The lagged spot price $p_{t-1}$ is a superior alternative. $p_{t}$ is observable and approximately equal to the marginal cost of gas (and therefore water) adjusted for the spark gap (See Evans and Guthrie (2009)). Thus, $p_{t-1}$, which is not endogenous, might well approximate the short-run marginal cost of the generators.

We use daily frequency data from $22 / 01 / 2004$ to $30 / 11 / 2010$. The daily frequency is consistent with approximating the continuous time assumption of our spot price model. The adopted data range corresponds to the maximum interval of negotiated forward contracts that we obtained for the New Zealand electricity market (NZEM).

The Haywards node spot price is assumed to be a proxy for the national spot price $p_{t}$. The demand variable $w_{1 t}$ is defined as the NZ national daily offtake (in Gwh). We analyze two variables as the cost shifter $w_{2 t}$ : the water inflow to the NZ hydro system and the lagged spot price $p_{t-1}$. The source for all these variables is the New Zealand Electricity Commission. ${ }^{15}$ The forward prices are extracted from the negotiated Haywards monthly and quarterly forward contracts. As mentioned before, the data is irregular and unbalanced since there are days with no trade and overlapping contracts of different maturity or nature. The source for the forward prices is the EnergyHedge website. ${ }^{16}$ Both the spot prices and the forward prices are adjusted for the New Zealand Consumer Price Index (CPI).

\footnotetext{
${ }^{13}$ According to the same authors, the exceptions correspond to the rare situations where lakes are entirely full.

${ }^{14}$ While obviously the case for hydro it also holds for gas in the absence of a spot market and limitations of gas supply. See Evans and Guthrie (2009).

${ }^{15}$ The data was specifically extracted from the centralised dataset (CDS) available at http://www.ea.govt.nz/industry/modelling/cds/ (accessed on 20/06/2011). There is no daily aggregate data of water inflow available. The daily water inflow to NZ $\left(w_{2 t}\right)$ was built from the sum of the daily inflows to the hydro systems described by Table 1 of Harte, Pickup, and Thomson (2004).

${ }^{16}$ The data was collected at http://www.energyhedge.co.nz (accessed on 30/01/2011). The website is not currently available since the EnergyHedge company signed an agreement with the Australian Stock Exchange (ASX) at 03/06/2011.
} 


\subsection{First step}

The empirical estimation of the spot market parameters requires the discretization of the continuous equations (13-16), which yields the following equations:

$$
\begin{aligned}
x_{1 \hat{t}} & =w_{1 \hat{t}}-f(\hat{t}) \\
x_{1 \hat{t}} & =\left(1-\frac{\hat{\psi}}{365}\right) x_{1 \hat{t}-1}+\epsilon_{1 \hat{t}} \\
w_{2 \hat{t}} & =w_{2 \hat{t}-1}+\frac{\hat{\mu}}{365}+\epsilon_{2 \hat{t}}
\end{aligned}
$$

Define $\hat{t}$ as a discrete period of time (In our case, a day). Following the approach of Lucia and Schwartz (2002), we define the deterministic component of the demand variable as the following cosine function:

$$
f(\hat{t})=\zeta+v \cos \left(\frac{\hat{t}}{365}+\tau\right)
$$

The advantage of this approach over the use, for example, of dummy variables to model seasonality is that $f(\hat{t})$ is continuous and easily integrable. Most forward contracts in New Zealand involve the delivery in a specific month or quarter. The integrability of $f(\hat{t})$ allows for a closed-form solution for the forward price of these average periods. Later, we show that this definition of $f(\hat{t})$ fits the demand behavior quite closely. Taking into account $f(\hat{t})$ and the equations (18-20), the spot price formation is defined by the following system of equations:

$$
\begin{aligned}
p_{\hat{t}} & =a+\frac{b}{K} w_{1 \hat{t}}+\rho w_{2 \hat{t}}+\epsilon_{\hat{t}} \\
w_{1 \hat{t}} & =f(\hat{t})+\left(1-\frac{\hat{\psi}}{365}\right)\left(w_{1 \hat{t}-1}-f(\hat{t}-1)\right)+\epsilon_{1 \hat{t}} \\
w_{2 \hat{t}} & =w_{2 \hat{t}-1}+\frac{\hat{\mu}}{365}+\epsilon_{2 \hat{t}} \\
f(\hat{t}) & =\zeta+v \cos \left(\frac{\hat{t}}{365}+\tau\right)
\end{aligned}
$$

The spot price model parameters are estimated by the seemingly unrelated regression method (SUR), where $\epsilon_{\hat{t}}, \epsilon_{1 \hat{t}}$ and $\epsilon_{2 \hat{t}}$ are assumed to be independent, to have zero mean and to have a finite covariance matrix. ${ }^{17}$ That is, we assume that the right hand side variables of the system are all exogenous. This is consistent with the theoretical assumptions of the model since $\vec{W}$ is by definition exogenous. Thus, we are strictly concerned about the estimation of the conditional expectations of equations (21-24). Define $w_{2 \hat{t}}$ as the NZ aggregate water inflow as previously explained. The estimation results are given by Table 2 . Notice that both the demand and the water inflows are statistically significant.

\footnotetext{
${ }^{17}$ See Greene and Zhang (2003) chapter 14.
} 
Table 2: Estimation Results: $w_{2 \hat{t}}=$ water Inflows. Equations (21-24). Data: NZ Electricity Commission

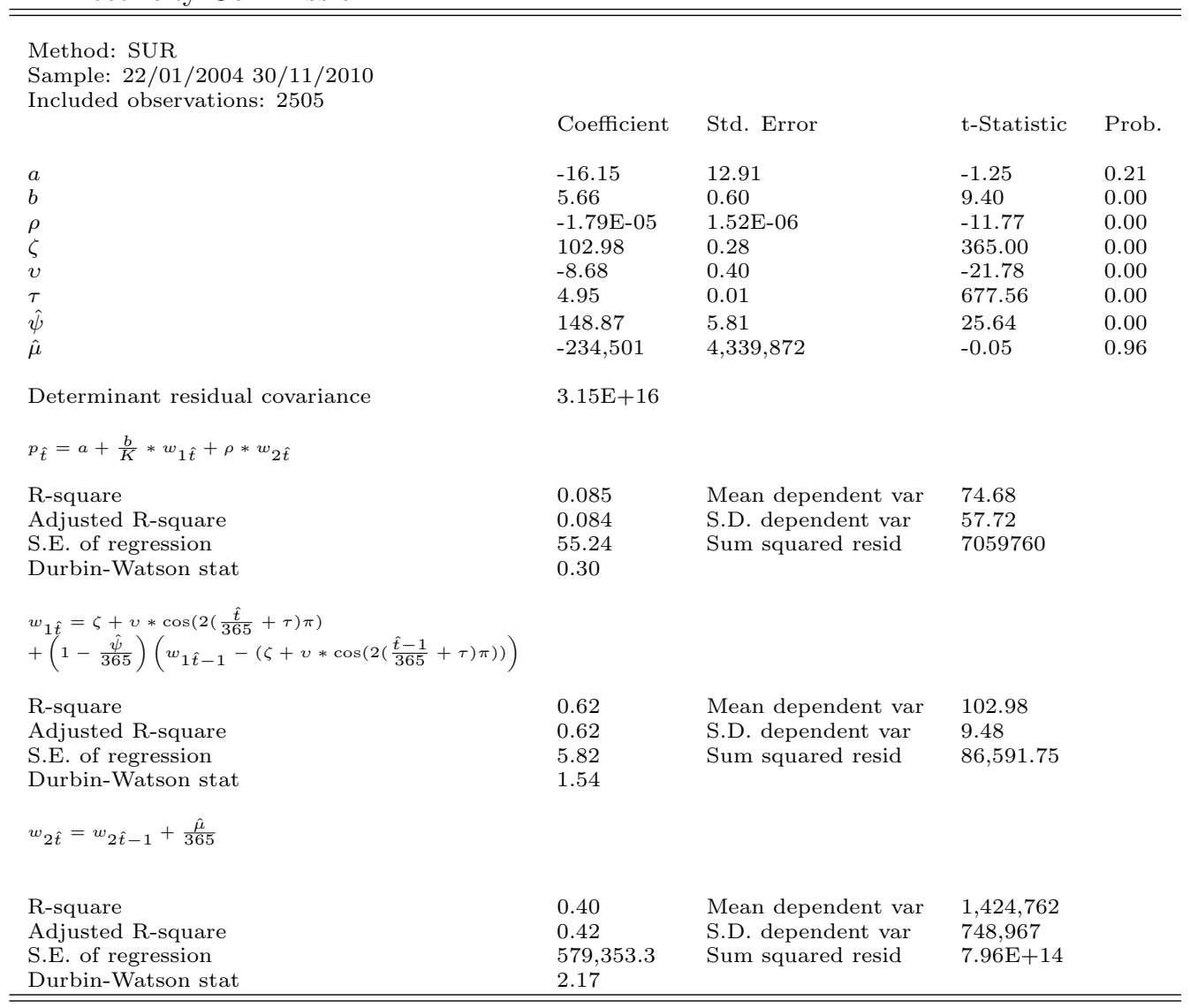


Their parameters also present the expected signs. Positive shifts in the demand and negative changes in the water inflows increase the equilibrium spot price $(b>0$ and $\rho<0)$. The remaining results show that the aggregate demand is reasonably (and significantly) explained by the deterministic function $f(\hat{t})$. As the magnitude and significance of $\hat{\psi}$ suggests, the demand reverts quickly to $f(\hat{t})$. Figure 4 illustrates this result. On the other hand, the water inflows' drift

Figure 4: Demand - NZEM Offtake (Gwh). Function $\mathrm{f}(\mathrm{t})$ given by equation (24): $\hat{\zeta}=102.98, \hat{v}=-8.68$ and $\hat{\tau}=4.95$. Data: NZ electricity Commission.

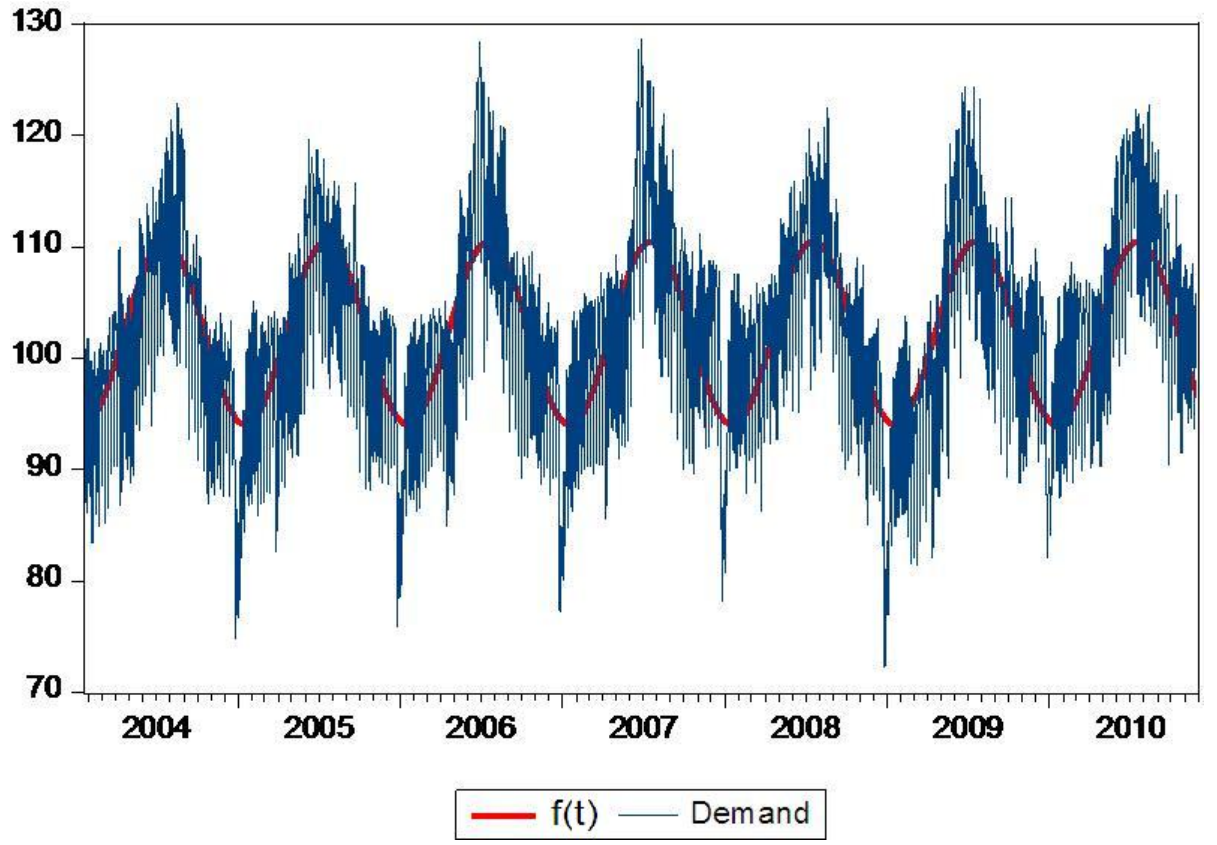

$\hat{\mu}$ is not statistically different from zero. This is not surprising since inflows are stationary. Besides, the $R^{2}$ of the spot price equation is almost insignificant $(<10 \%)$ with a serious autocorrelation problem, expressed by a Durbin-Watson (DW) statistic very different from 2. This (and the significance of the autoregressive component $p_{\hat{t}-1}$ expressed in Table 3 ) indicates that the hypothesis of $\operatorname{cov}\left(\epsilon_{\hat{t}}, \epsilon_{\hat{t}-1}\right)=0$ does not hold. This is evidence that the water inflows $w_{2 \hat{t}}$ alone do not satisfactorily capture the generators' marginal cost behavior. Several combinations of $w_{2 \hat{t}}$ and other related variables such as water storage and gas generation were tried. All failed to attain serially uncorrelated results. ${ }^{18}$

In fact, as shown by Lucia and Schwartz (2002) and Mason (2002), $p_{\hat{t}}$ presents a strong autoregressive component. In our second approach, we assume that the observed price is a good proxy available for capturing shifts in the

\footnotetext{
${ }^{18}$ Serial correlation affects the quality of estimates and mean that the best forecast of $p_{\hat{t}}$ is not the estimated equation.
} 
Table 3: Estimation Results: $w_{2 \hat{t}}=p_{\hat{t}-1}=$ lagged spot price. Equations (2124). Data: NZ Electricity Commission

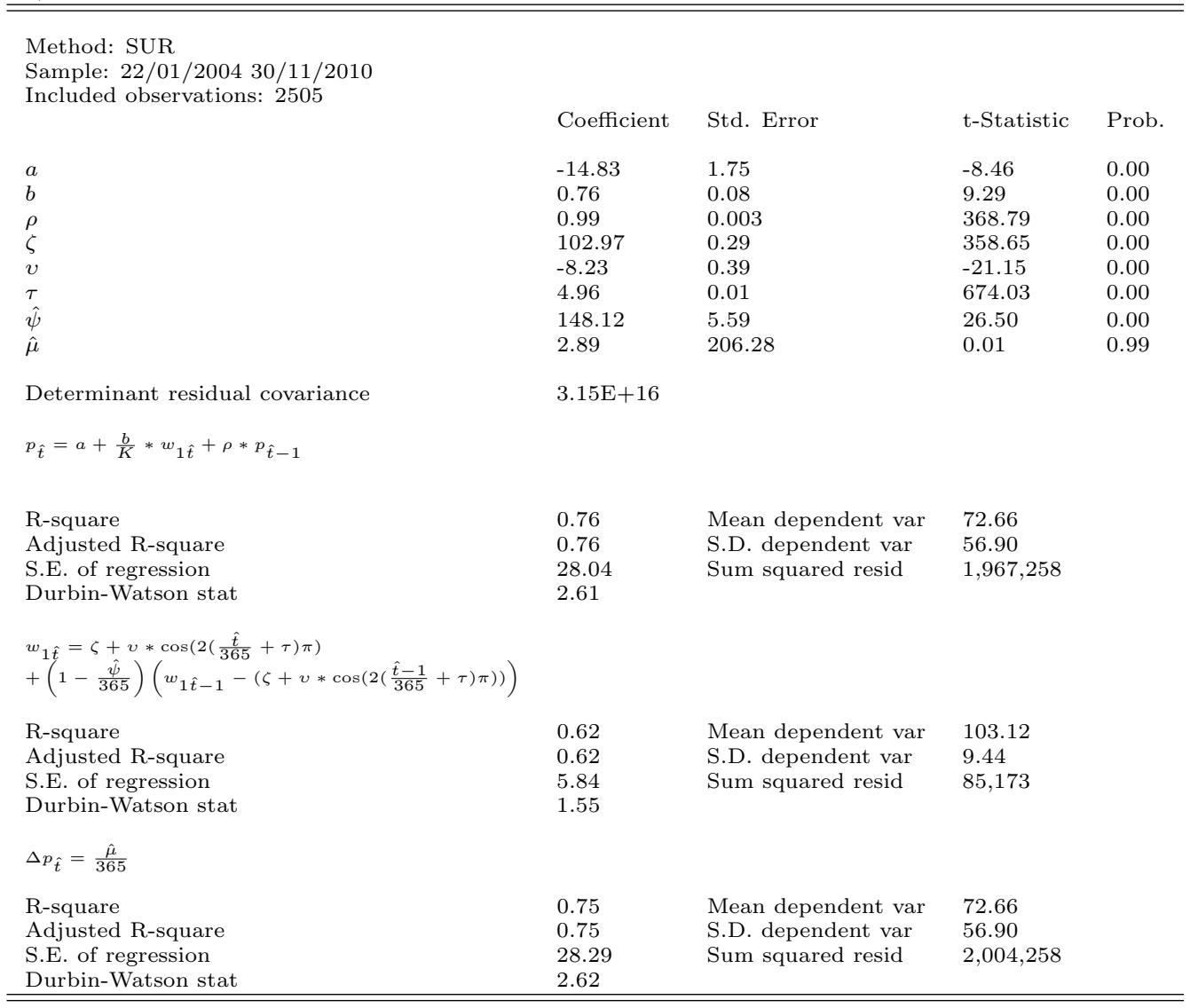

marginal costs. Specifically, we assume for the reason given earlier, the lagged price $p_{\hat{t}-1}$ is a good empirical proxy for $w_{2 \hat{t}}$. Including $p_{\hat{t}-1}$ in the regression increases the goodness-of-fit given by the $R^{2}$, and it considerably attenuates the serial correlation problem (see Table 3). All the remaining parameter estimates of Table 3 yield results similar to the previous exercise using the other proxies for marginal cost. The fast mean reversion of the aggregate demand to a significant deterministic function remains. Again, the drift $\hat{\mu}$ is insignificant.

The lagged spot price alone does not exhaust all the time series possibilities of the daily electricity spot price in the NZEM market. A purely empirical seasonal autoregressive integrated moving average (SARIMA) approach would suggest the additional consideration of moving average and autoregressive components. ${ }^{19}$ However, the object of this subsection is to test and estimate our spot price model taking into account the NZEM data and the results of Table 3 show

${ }^{19}$ See Enders (1995) for an introductory discussion about SARIMA models. 
that our model fits well the actual NZEM data. First, all the parameters are statistically significant, with the exception of the drift $\hat{\mu}$ which is not expected to be different from zero. Second, the explanatory power of the equilibrium spot price equation is reasonable $\left(R^{2} \approx 75 \%\right)$. Last, the serial correlation problem is attenuated with the adoption of $p_{\hat{t}-1}$ as a proxy to $w_{2 \hat{t}}$.

In summary, this second approach fits closely the actual NZEM data between $22 / 01 / 2004$ and 30/11/2010. The equilibrium and dynamic parameters are statistically significant with the expected signs. The second step in the forward price modeling is the calibration of the market prices of risk $\left(\lambda_{1}\right.$ and $\left.\lambda_{2}\right)$ from the actual forward price data.

\subsection{Second step}

The next step in the implementation of our model involves calibrating the demand market price of risk $\left(\lambda_{1}\right)$ and the supply market price of risk $\left(\lambda_{2}\right)$. We use the non linear least squares (LS) approach. That is, we choose the $\lambda$ 's that minimize the sums of the squares of deviation between the observed forward prices and the theoretical formula given by equation (25). Notice that equation (17) refers to the forward price at $t$ of delivering electricity at the future instant $T$. However, electricity contracts are not instantaneous. They entail a specific time interval. The Haywards forward contracts used in our exercise refer to monthly and quarterly periods of time. That is, the observed forward price $\hat{P C} C_{t}$ refers to the forward price cleared at $t$ of a fixed flow of electricity to be delivered between $T_{1}$ and $T_{2}$, with $T_{2}-T_{1}$ being a month or a quarter. Therefore instead of directly using equation (17) for pricing, we use its integral between the maturities $T_{1}$ and $T_{2}$. That is, we use the following equation:

$$
\overline{P C}_{t}^{T_{1}, T_{2}}=\int_{T_{1}}^{T_{2}} P C\left(t, T, w_{1 t}, w_{2 t}, \hat{\theta}, \hat{\lambda_{1}}, \hat{\lambda_{2}}\right) d T
$$

Where $\hat{\theta}$ is a vector that comprises all the estimated parameters of Table 3 , including the standard deviations: we consider the conditional standard deviations of demand $s_{1}$ and spot price $s_{2}$ as proxies for volatility in our calibration exercise. In addition, we adjust these daily volatilities for the annual basis in which the dynamic processes are defined ( $t$ is proportional to a year). That is, we use $\hat{\sigma}_{1}=s_{1} \sqrt{365}=5.84 \sqrt{365}$ and $\hat{\sigma}_{2}=s_{2} \sqrt{365}=28.29 \sqrt{365}$. The calibrated market prices of risk for the Haywards contracts between 22/01/2004 and $30 / 11 / 2010$ are then $\hat{\lambda}_{1}=3.63$ and $\hat{\lambda}_{2}=0.005$. Now, we have all the elements for constructing an estimated forward price curve. Consider a monthly contract. For illustrative purposes, assume that $t=0$ (We price the forward contracts at the first day of the year) and that the demand and cost shifter are, respectively, estimated by the sample means $\hat{E}\left(w_{1}\right)=103.12$ and $\hat{E}\left(w_{2}\right)=\hat{E}(p)=72.66$. Figure 5 shows that spot market concentration in fact affects forward prices in the NZEM market. As expected, an increase in the number of firms decreases forward prices significantly. For example, the peak $P C$ varies from around NZD70.00, in a market with 7 firms, to more than NZD85.00, in a market with 
Figure 5: Market concentration and forward prices in the New Zealand Electricity Market (NZEM). Equations (21-24). Parameters: Table 3. Data: NZ Electricity Commission

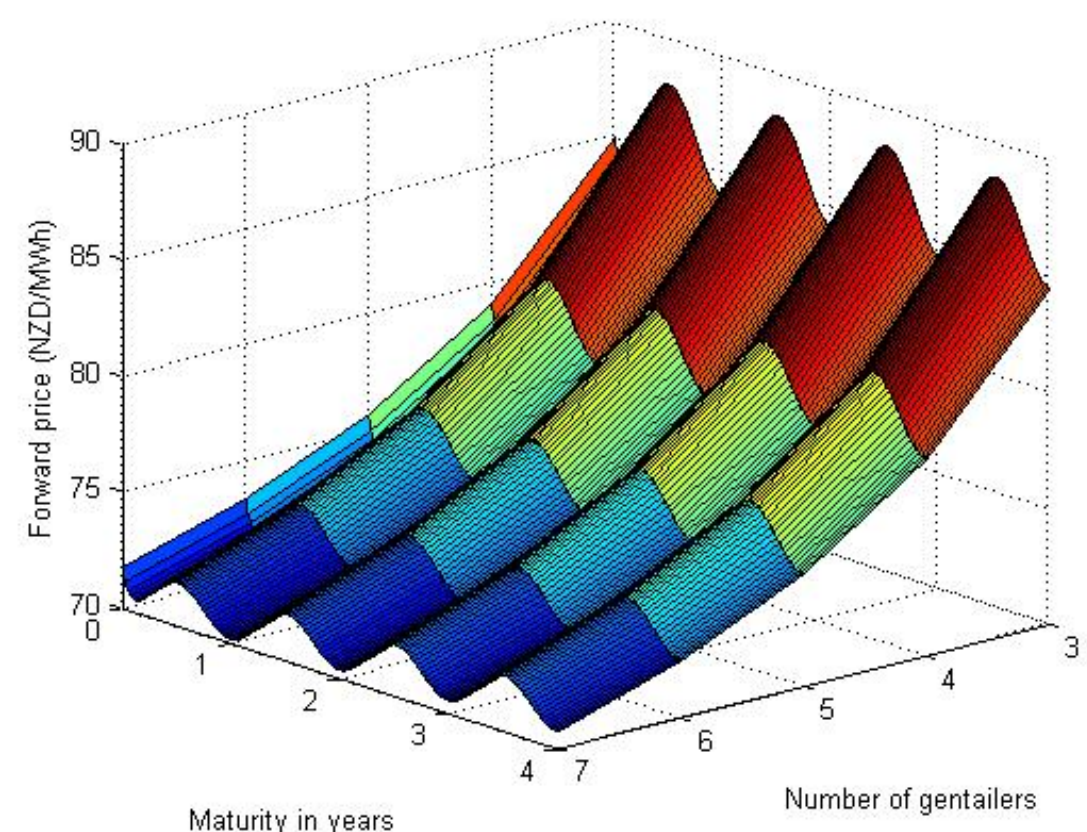

just 3 firms (increase of more than 20\%). We observe that the NZEM calibrated forward curve is essentially flat. The demand seasonal pattern clearly dictates the forward curve shape.

\section{Conclusion}

Our model shows that even when dealing with electricity markets characterized by oligopoly, existence of forward market, vertical integration and uniform price auctions, we can build hybrid price models over a simple relationship between spot price and state variables affecting firms' costs and aggregate demand. Specifically, under reasonable approximations concerning generators' production function and consumers' aggregate demand, this relationship is linear and all the market structure information is embedded in the parameters of the spot price formation rule.

We consider the existence of two state variables: the aggregate demand and the shadow price of fuel (water and gas) moving marginal cost functions. Assuming similar stochastic processes to Lucia and Schwartz (2002) and applying their two factor arbitrage model results over our equilibrium spot price forma- 
tion rule (equation (8)), we derive a closed form forward price (equation (17)). Several results can be derived from comparative statics. Increases in either volatility or the price of risk of both demand and shadow price of fuel decrease the price of forward contracts. The opposite happens when raising the fuel shadow price's drift or the current value of both state variables. Positive shifts in the generators' cost functions or in the deterministic portion of aggregate demand also move forward prices upwards.

We use an illustrative numerical example (Figure 1) to show that a decrease in the number of generators can shift the forward curve positively. In particular, controlling for the efficiency effect of an increase in concentration, Figure 2 shows that market power in the spot market can be transferred to the forward market.

According to our model, there are two market structures where the spot price is not influenced by firms' forward positions. The first one is the case of perfectly competitive markets. The second corresponds to electricity markets where all the retailers are actually gentailers $(K=N)$. In this situation, the forward net positions of all the retailers would be reflected in the gentailers' optimal supply strategies. If the participation of outside speculators in the forward market is negligible, as we assumed, the impact of forward contracts on the aggregate supply curve is completely offset when all the generators' (gentailers included) individual supplies are aggregated. This case can be thought of as an approximation for markets with a high degree of vertical integration as is the case in New Zealand or Spain. Notice that this assumption allows for differences across gentailers in their participation in wholesale and retail market. That is, the market is allowed to be composed by net retailers and net generators. This assumption also means that, despite the average Lerner index in such fully vertically integrated markets being equal to zero according to our model, individual net gentailers exert spot market power.

We assume $K=N$ as a good approximation for the New Zealand electricity market (see Table 1) and apply a two-stage empirical methodology implementing the model for the NZEM market. Our model fits the data reasonably and confirms the relevance of spot market concentration in affecting forward prices.

In summary, this paper develops the link between market structure and forward prices. We show that if the market becomes less concentrated the forward curve can be shifted or rotated. Specifically, generators' market power in the spot market can inflate forward prices and translate into market power in the hedge market.

\section{References}

Allaz, B. and J-L. Villa (1993), Cournot competition, forward Markets and efficiency, Journal of Economic Theory 59, 1-16.

Anderson, E.J. and A.B. Philpott (2002), Using supply functions for offering generation into an electricity market, Operations Research 477-489. 
Anderson, E.J. and H. Xu (2002), Necessary and sufficient conditions for optimal offers in electricity markets, SIAM Journal on Control and Optimization $41,1212-1228$.

Barlow, M. T. (2002), A diffusion model for electricity prices, Mathematical Finance 287-298.

Bolle, F. (1992), Supply function equilibria and the danger of tacit collusion: The case of spot markets for electricity, Energy Economics 14, 94-102.

Bushnell, J. (2007), Oligopoly equilibria in electricity contract markets, Journal of Regulatory Economics 32, 225-245.

Cartea, A. and P. Villaplana (2005), Pricing in electricity markets: a mean reverting jump diffusion model with seasonality, Applied Mathematical Finance $313-335$.

- (2008), Spot price modeling and the valuation of electricity forward contracts: The role of demand and capacity, Journal of Banking \& Finance 32, 2502-2519, URL http://ideas.repec.org/a/eee/jbfina/v32y2008i12p2502-2519.html.

Deng, S. (2000), Stochastic models of energy commodity prices and their applications: mean-reversion with jumps and spikes (University of California Energy Institute).

Dixit, A. (1983), Vertical integration in a monopolistically competitive industry, International Journal of Industrial Organization 1, 63-78.

Enders, W. (1995), Applied econometric time series (Wiley).

Evans, L. and G Guthrie (2009), How options provided by storage affect electricity prices, Southern Economic Journal 75, 681-702, URL http://ideas.repec. org/a/sej/ancoec/v753y2009p681-702.html.

Evans, L.T., G.A. Guthrie, and A. Lu (2010), A New Zealand electricity market model: assessment of the effect of climate change on electricity production and consumption.

Ferreira, J.L. (2003), Strategic interaction between futures and spot markets, Journal of Economic Theory 108, 141-151.

Gans, J.S., F.A. Wolak, and VIC Carlton (2008), A comparison of ex ante versus ex post vertical market power: evidence from the electricity supply industry, Technical report, Working paper, SSRN.

Green, R.J. (1999), The electricity contract market in England and Wales, Journal of Industrial Economics 47, 107-124.

Green, R.J. and C. Le Coq (2006), The length of the contract and collusion, CSEM working paper 154. 
Green, R.J. and D.M. Newbery (1992), Competition in the British electricity spot market, Journal of political economy 929-953.

Greene, W. and C. Zhang (2003), Econometric analysis, volume 5th Edition (Prentice hall New Jersey).

Harte, D., M. Pickup, and PJ Thomson (2004), Stochastic models for hydro catchment inflows: an exploratory analysis, A report commissioned by the New Zealand Electricity Commission .

Hogan, S. (2010), Does wholesale market power extend to fixed-price forward prices in electricity markets? .

Holmberg, P. and D. Newbery (2010), The supply function equilibrium and its policy implications for wholesale electricity auctions, Utilities Policy 18, 209-226.

Hortacsu, A. and S.L. Puller (2005), Understanding strategic bidding in restructured electricity markets: a case study of ERCOT, NBER Working Paper

(2008), Understanding strategic bidding in multi-unit auctions: a case study of the Texas electricity spot market, The RAND Journal of Economics $39,86-114$.

Kastl, J. (2006), Discrete bids and empirical inference in divisible good auctions, Mimeo, Department of Economics, Stanford University. .

(2008), On the properties of equilibria in private value divisible good auctions with constrained bidding, Mimeo, Department of Economics, Stanford University. .

Klemperer, P.D. and M.A. Meyer (1989), Supply function equilibria in oligopoly under uncertainty, Econometrica 57, 1243-1277.

Liski, M. and J-P. Montero (2006), Forward trading and collusion in oligopoly, Journal of Economic Theory 131, 212-230.

Lucia, J. and E.S. Schwartz (2002), Electricity prices and power derivatives: evidence from the nordic power exchange, Review of Derivatives Research $5-50$.

Lyle, M. R. and R. J. Elliott (2009), A simple hybrid model for power derivatives, Energy Economics 31, 757-767.

Mahenc, P. and F. Salanie (2004), Softening competition through forward trading, Journal of Economic Theory 116, 282-293.

Mason, G.M. (2002), A comparison of restructured electricity pools, the key characteristics of NZEM spot prices, and the estimation of a two-factor mean reverting model, $\mathrm{Ph} . \mathrm{D}$. thesis. 
Newbery, D.M. (1998), Competition, contracts and entry in the electricity spot market, Rand Journal of Economics 29.

Pirrong, C. and M. Jermakyan (2008), The price of power: The valuation of power and weather derivatives, Journal of Banking and Finance.

Schwartz, E.S. (1997), The stochastic behavior of commodity prices: implications for valuation and hedging, Journal of Finance 52, 923-974.

Schwartz, E.S. and J.E. Smith (2000), Short-term variations and long-term dynamics in commodity prices, Management Science 46, 893-911.

Skantze, P., A. Gubina, and M. Ilić (2000), Bid-based stochastic model for electricity prices: the impact of fundamental drivers on market dynamics (Massachusetts Institute of Technology Cambridge, Energy Laboratory).

Von der Fehr, N.-H. M. and D. Harbord (1993), Spot market competition in the UK electricity industry, Economic Journal 103, 531-546.

Wilson, Robert (1979), Auctions of shares, The Quarterly Journal of Economics 93, 675-89, URL http://ideas.repec.org/a/tpr/qjecon/v93y1979i4p675-89.html. 


\section{A Proof of lemma 2.1}

To solve this maximization problem we need first to integrate by parts the objective function. Suppressing the $i$ and $t$ indices we have, modulo a constant term:

$$
\begin{aligned}
-\int_{0}^{\bar{p}} \quad U^{\prime}\left(S(p) p-C(S(p), \vec{W})-(p-P C) Q C-m_{i}\left(p-p^{R}\right) D\left(p_{t}^{R}, \vec{W}_{t}\right)\right) \\
\quad \times\left(S^{\prime}(p) p-C^{\prime}(S(p), \vec{W}) S^{\prime}(p)-Q C\right) H(p, S(p) ; Q C) d p .
\end{aligned}
$$

Labeling the integrand:

$$
\begin{aligned}
F= & -U^{\prime}\left(S(p) p-C(S(p), \vec{W})-(p-P C) Q C-m\left(p-p^{R}\right) D\left(p_{t}^{R}, \vec{W}_{t}\right)\right) \\
& \times\left(S^{\prime}(p) p+S(p)-C^{\prime}(S(p), \vec{W}) S^{\prime}(p)-Q C-m D\left(p_{t}^{R}, \vec{W}_{t}\right)\right) \\
& \times H(p, S(p) ; Q C) .
\end{aligned}
$$

From the calculus of variation, the Euler-Lagrange necessary condition for the optimal $S(p)$ is given by:

$$
\frac{d}{d p} F_{S^{\prime}}=F_{S}
$$

Evaluating the derivatives:

$$
\begin{aligned}
-F_{S}= & \left.H_{S} U^{\prime}(.)\left[p S^{\prime}+S-C^{\prime}(S, \vec{W}) S^{\prime}-Q C-m D\left(p_{t}^{R}, \vec{W}_{t}\right)\right)\right] \\
& \left.+H U^{\prime \prime}(.)\left(p-C^{\prime}(S, \vec{W})\right)\left[p S^{\prime}+S-C^{\prime}(S, \vec{W}) S^{\prime}-Q C-m D\left(p_{t}^{R}, \vec{W}_{t}\right)\right)\right] \\
& +H U^{\prime}(.)\left[1-C^{\prime \prime}(S, \vec{W}) S^{\prime}\right] \\
-F_{S^{\prime}}= & H U^{\prime}(.)\left[p-C^{\prime}(S, \vec{W})\right] .
\end{aligned}
$$

And taking the total derivative of $F_{S^{\prime}}$ with respect to $p$ :

$$
\begin{aligned}
-\frac{d}{d p} F_{S^{\prime}}= & H_{p} U^{\prime}(.)\left[p-C^{\prime}(S, \vec{W})\right]+H_{S} S^{\prime} U^{\prime}(.)\left[p-C^{\prime}(S, \vec{W})\right] \\
& \left.+H U^{\prime \prime}(.)\left[p S^{\prime}+S-C^{\prime}(S, \vec{W}) S^{\prime}-Q C-m D\left(p_{t}^{R}, \vec{W}_{t}\right)\right)\right]\left(p-C^{\prime}(S, \vec{W})\right) \\
& +H U^{\prime}(.)\left(1-C^{\prime \prime}(S, \vec{W}) S^{\prime}\right) .
\end{aligned}
$$

Equating and canceling terms we get:

$$
\left.H_{S} U^{\prime}(.)\left(S-Q C-m D\left(p_{t}^{R}, \vec{W}_{t}\right)\right)\right)=H_{p} U^{\prime}(.)\left(p-C^{\prime}(S, \vec{W})\right) .
$$

Considering again the $i$ and $t$ indices we have:

$$
\left.p-M C_{i t}\left(S_{i t}^{*}(p), \vec{W}_{t}\right)=\left[S_{i t}^{*}(p)-Q C_{i t}-m_{i} D\left(p_{t}^{R}, \vec{W}_{t}\right)\right)\right] \frac{H_{S}\left(p, S_{i t}^{*}(p) ; Q C_{i t}\right)}{H_{p}\left(p, S_{i t}^{*}(p) ; Q C_{i t}\right)} .
$$




\section{B Proof of lemma 2.2}

Suppose that,

$$
S_{i}\left(p, Q C_{i}, \vec{W}\right)=\alpha_{i}(p)+\beta_{i}\left(Q C_{i}\right)+\sum_{j=1}^{L} \delta_{k i}\left(w_{k}\right) .
$$

Given that we can use the market clearing condition to represent the event $\operatorname{Pr}\left(p_{t}^{c} \leq p \mid Q C_{i}, S_{i}(p)\right)$ :

$$
\sum_{j \neq i} \beta_{j}\left(Q C_{j}\right)+\sum_{j \neq i} \sum_{k=1}^{M} \delta_{k j}\left(w_{k}\right) \geq D\left(p^{R}, \vec{W}_{t}\right)-S_{i}-\sum_{j \neq i} \alpha_{j}(p) .
$$

The left hand side of this inequality can be labeled as a (bidder specific) random variable, $\theta_{i}$ that does not depend on $p$, and the right hand side is a deterministic function of price. Let $\Gamma_{i}($.$) denote the cdf of \theta_{i}$ and $\gamma_{i}($.$) denote the pdf (both$ conditional on the bidder's contract quantity $\left.Q C_{i}\right)$. Given these:

$$
\begin{aligned}
H_{p}\left(p, S_{i} ; Q C_{i}\right)= & \frac{\partial}{\partial p} \operatorname{Pr}\left(p_{t}^{c} \leq p \mid Q C_{i}, S_{i}\right) \\
= & \frac{\partial}{\partial p} \operatorname{Pr}\left(\theta_{i} \geq D\left(p^{R}, \vec{W}_{t}\right)-S_{i}-\sum_{j \neq i} \alpha_{j}(p)\right) \\
= & \frac{\partial}{\partial p}\left[1-\Gamma_{i}\left(D\left(p^{R}, \vec{W}_{t}\right)-S_{i}-\sum_{j \neq i} \alpha_{j}(p)\right)\right] \\
= & -\gamma_{i}\left(D\left(p^{R}, \vec{W}_{t}\right)-S_{i}-\sum_{j \neq i} \alpha_{j}(p)\right) \frac{\partial}{\partial p}\left(D\left(p^{R}, \vec{W}_{t}\right)\right. \\
& \left.-S_{i}-\sum_{j \neq i} \alpha_{j}(p)\right),
\end{aligned}
$$

and

$$
\begin{aligned}
H_{S}\left(p, S_{i} ; Q C_{i}\right)= & \frac{\partial}{\partial S_{i}} \operatorname{Pr}\left(p_{t}^{c} \leq p \mid Q C_{i}, S_{i}\right) \\
= & -\gamma_{i}\left(D\left(p^{R}, \vec{W}_{t}\right)-S_{i}-\sum_{j \neq i} \alpha_{j}(p)\right) \frac{\partial}{\partial S_{i}}\left(D\left(p^{R}, \vec{W}_{t}\right)\right. \\
& \left.-S_{i}-\sum_{j \neq i} \alpha_{j}(p)\right) .
\end{aligned}
$$

Evaluating the derivatives gives $\frac{H_{p}\left(p, S_{i} ; Q C_{i}\right)}{H_{S}\left(p, S_{i} ; Q C_{i}\right)}=-\left[\frac{\partial D\left(p^{R}, \vec{W}_{t}\right)}{\partial p}-\sum_{j \neq i} \alpha_{j}^{\prime}(p)\right]$, which is the derivative in respect to price of the residual demand faced by firm $i$. By definition of the aggregate demand, $\frac{\partial D\left(p^{R}, \vec{W}_{t}\right)}{\partial p}=0$. 
Substituting these results in the equation (??), defining the marginal cost $C_{i}^{\prime}\left(S_{i}(p), \vec{W}\right)$ as $M C_{i}\left(S_{i}, \vec{W}\right)$ and considering again the index $t$, we yield the following equation:

$$
\begin{aligned}
p_{t}-M C_{i t} & =-\frac{S_{i t}-Q C_{i t}-m_{i} D_{t}}{\frac{\partial D_{t}}{\partial p_{t}}-\frac{\partial \sum_{j \neq i} S_{j t}}{\partial p_{t}}} \\
p_{t}-M C_{i t} & =\frac{S_{i t}-Q C_{i t}-m_{i} D_{t}}{\frac{\partial \sum_{j \neq i} S_{j t}}{\partial p_{t}}} .
\end{aligned}
$$

Now let's consider $q_{i t}^{\prime}=D_{t}-\sum_{j \neq i} S_{j t}-Q C_{i t}-m_{i} D_{t}$. The elasticity $\varepsilon_{i t}^{\prime}$ is equal to $-\frac{d q_{i t}^{\prime}}{d p_{t}} \frac{p_{t}}{q_{i t}}$. Observe that $\frac{d q_{i t}^{\prime}}{d p_{t}}=-\frac{\partial \sum_{j \neq i} S_{j t}}{\partial p_{t}}$ and, in equilibrium, $D_{t}-$ $\sum_{j \neq i} S_{j t}=S_{i t}$. Therefore $q_{i t}^{\prime}=S_{i t}-Q C_{i t}-m_{i} D_{t}$ and,

$$
\frac{p_{t}-M C_{i t}}{p_{t}}=\frac{1}{\varepsilon_{i t}^{\prime}\left(q_{i t}^{\prime}\right)} .
$$

\section{Proof of proposition 2.3}

For all $i=1,2 \ldots, N$, assume $\alpha_{i}>0$ and that generator $i$ is restricted to the following linear supply strategy:

$$
S_{i}\left(p, Q C_{i}, \vec{W}\right)=\phi_{i}+\alpha_{i} p+\beta_{i} Q C_{i}+\sum_{j=1}^{L} \delta_{k i} w_{k} .
$$

To prove the first and second order conditions (FOC and SOC) we use the conditions for a local maximum in Anderson and Xu (2002). ${ }^{20}$ Definition 2.12 ensures that a maximum for this problem exists, by Theorem 3 of Anderson and $\mathrm{Xu}(2002)$.

The key variable in their calculations is $Z=R_{q} \psi_{p}-R_{p} \psi_{q}$ where (in our notation)

$$
R=U(\pi)
$$

$q$ is the quantity supplied and $p$ is the price at which it is supplied. $\psi(p, q)$ is the probability that the point $(p, q)$ lies above the residual demand that the firm in question is facing. In other words:

$$
\psi=\operatorname{Prob}\left(D-\sum_{j \neq i} S_{j}(p)<q\right)
$$

where $\tilde{D}$ is demand. For the particular case of linear supply curves (equation (26)), we can write

$$
\psi=\operatorname{Prob}(D-\tilde{A}-B p<q)
$$

\footnotetext{
${ }^{20}$ Note that this is a local condition, not a global one. So it is conceivable to have multiple points satisfying these conditions. However, our necessary condition is only satisfied by one set of supply curves. If no other curves satisfy the necessary condition, then simply showing that your curve satisfies the sufficient condition for a local maximum makes it a global maximum.
} 
where $\tilde{A}$ is the uncertain aggregate constant term of the other firms' supply (uncertain due to their $Q C$ values) and $B$ is the total slope of their supply curve. For this case, I will define a function $\phi$ such that

$$
\psi=\phi\left(B p+q, w_{t}\right) .
$$

$\phi_{1}$ is the derivative of $\phi$ with respect to the first term $\left(\phi_{11}\right.$ is the second derivative).

\section{C.1 Necessary Condition}

From Anderson and Philpott (2002) and Anderson and Xu (2002), $Z\left(S_{i}, p\right)=0$ is a necessary condition for a maximum. Then,

$$
\begin{aligned}
Z\left(S_{i}, p\right) & =R_{S_{i}}\left(S_{i}, p\right) \psi_{p}\left(S_{i}, p\right)-R_{p}\left(S_{i}, p\right) \psi_{S_{i}}\left(S_{i}, p\right)=0 \\
& \Rightarrow U^{\prime}(.)\left(p-C^{\prime}\left(S_{i}\right)+m_{i}\left(P^{R}-p\right)\right) H_{p} \\
& =U^{\prime}(.)\left(S_{i}-Q C_{i}-m_{i} S(p)+m_{i}\left(P^{R}-p\right) \sum_{i \neq j} S_{j}^{\prime}(p)\right) H_{S}
\end{aligned}
$$

Given that the demand is inelastic, we know that:

$$
\begin{aligned}
H_{p} & =-\left(\frac{\partial D(p, \vec{W})}{\partial p}-\sum_{i \neq j} \alpha_{i}\right) H_{S_{i}} \\
H_{S_{i}} & =\frac{1}{\sum_{i \neq j} \alpha_{i}} H_{p}
\end{aligned}
$$

In this case, we have:

$$
\begin{aligned}
& \left(p-C^{\prime}\left(S_{i}\right)+m_{i}\left(P^{R}-p\right)\right) U^{\prime}(.) H_{p} \\
= & \left(\frac{S_{i}-Q C_{i}-m_{i} S(p)}{\sum_{i \neq j} \alpha_{i}}+m_{i}\left(P^{R}-p\right) \frac{\sum_{i \neq j} \alpha_{i}}{\sum_{i \neq j} \alpha_{i}}\right) U^{\prime}(.) H_{p}
\end{aligned}
$$

Given $U^{\prime}()>$.0 , we have

$$
p-C^{\prime}\left(S_{i}\right)=\frac{S_{i}-Q C_{i}-m_{i} S}{\sum_{i \neq j} \alpha_{i}}
$$




\section{C.2 Sufficient Condition}

Now, define the constant $Q=\sum_{i \neq j} \alpha_{i}$. Notice that the necessary condition implies $Q R_{S_{i}}-R_{p}=0$

Given that $\psi_{p} \equiv H_{p}, Q>0, U^{\prime}()>0,. U^{\prime \prime}() \leq$.0 and $C^{\prime \prime}=b>0$, we have:

$$
\begin{aligned}
R_{S_{i} S_{i}=}= & U^{\prime \prime}(.)\left(p-C^{\prime}\left(S_{i}\right)+m_{i}\left(P^{R}-p\right)\right)^{2}-U^{\prime}(.) C^{\prime \prime}\left(S_{i}\right) \quad(<0) \\
R_{S_{i} p}= & U^{\prime \prime}(.)\left(p-C^{\prime}\left(S_{i}\right)+m_{i}\left(P^{R}-p\right)\right)\left(S_{i}-Q C_{i}-m_{i} S+m_{i}\left(P^{R}-p\right) Q\right) \\
& +\left(1-m_{i}\right) U^{\prime}(.) \quad(? ?) \\
R_{p p}= & U^{\prime \prime}(.)\left(S_{i}-Q C_{i}-m_{i} S+m_{i}\left(P^{R}-p\right) Q\right)^{2}-m_{i} U^{\prime}(.) Q \quad(<0) \\
\psi_{p p}= & H_{p p} \quad(>0) \\
\psi_{S_{i}}= & \frac{1}{Q} H_{p} \quad(>0) \\
\psi_{p S_{i}}= & \frac{1}{Q} H_{p p} \quad(? ?) \\
\psi_{S_{i} S_{i}=} & \frac{1}{Q^{2}} H_{p p} \quad(? ?) .
\end{aligned}
$$

According to Anderson and Philpott (2002) and Anderson and Xu (2002), the sufficient conditions for a linear supply curve to be a local maximum are $Z_{p}>0$ and $Z_{S_{i}}<0$.

$$
Z_{p}=R_{S_{i} p} \psi_{p}+R_{S_{i}} \psi_{p p}-R_{p p} \psi_{S_{i}}-R_{p} \psi_{S_{i} p}>0
$$

We know from the first order condition that $Q R_{S_{i}}-R_{p}=0$. Then we have the following:

$$
\begin{aligned}
& R_{S_{i}} \psi_{p p}-R_{p} \psi_{S_{i} p} \\
= & R_{S_{i}} H_{p p}-R_{p} \frac{1}{Q} H_{p p} \\
= & H_{p p}\left[Q R_{S_{i}}-R_{p}\right] \\
= & 0
\end{aligned}
$$

Therefore, we simplify the first condition $Z_{p}>0$ to:

$$
\begin{aligned}
Z_{p}= & R_{S_{i} p} \psi_{p}-R_{p p} \psi_{S_{i}} \\
= & U^{\prime \prime}(.)\left(p-C^{\prime}\left(S_{i}\right)+m_{i}\left(P^{R}-p\right)\right)\left(S_{i}-Q C_{i}-m_{i} S+m_{i}\left(P^{R}-p\right) Q\right) H_{p} \\
& +\left(1-m_{i}\right) U^{\prime}(.) H_{p}-\frac{1}{Q} U^{\prime \prime}(.)\left(S_{i}-Q C_{i}-m_{i} S+m_{i}\left(P^{R}-p\right) Q\right)^{2} H_{p}+\frac{1}{Q} U^{\prime \prime}(.) m_{i} U^{\prime}(.) H_{p} Q .
\end{aligned}
$$

From the first order condition, $p-C^{\prime}\left(S_{i}\right)+m_{i}\left(P^{R}-p\right)=\frac{1}{Q}\left(S_{i}-Q C_{i}-\right.$ $\left.m_{i} S+m_{i}\left(P^{R}-p\right) Q\right)$. Hence, the first and third term cancel out. 
Then,

$$
\begin{aligned}
Z_{p} & =R_{S_{i} p} \psi_{p}-R_{p p} \psi_{q} \\
& =+\left(1-m_{i}\right) U^{\prime}(.) H_{p}+m_{i} U^{\prime}(.) H_{p} \\
& =U^{\prime} H_{p}>0
\end{aligned}
$$

We still need to show that $Z_{S_{i}}<0$.

$$
Z_{S_{i}}=R_{S_{i} S_{i}} \psi_{p}+R_{S_{i}} \psi_{p S_{i}}-R_{p S_{i}} \psi_{S_{i}}-R_{p} \psi_{S_{i} S_{i}}<0
$$

Using again the first order condition $Q R_{S_{i}}-R_{p}=0$,

$$
\begin{aligned}
& R_{S_{i}} \psi_{p S_{i}}-R_{p} \psi_{S_{i} S_{i}} \\
= & R_{S_{i}} \frac{1}{Q} H_{p p}-R_{p} \frac{1}{Q^{2}} H_{p p} \\
= & {\left[Q R_{S_{i}}-R_{p}\right] H_{p} p } \\
= & 0
\end{aligned}
$$

Therefore, we simplify the second condition $\left(Z_{S_{i}}<0\right)$ to:

$$
\begin{aligned}
Z_{S_{i}}= & R_{S_{i} S_{i}} \psi_{p}-R_{p S_{i}} \psi_{S_{i}} \\
= & {\left[U^{\prime \prime}(.)\left(p-C^{\prime}\left(S_{i}\right)+m_{i}\left(P^{R}-p\right)\right)^{2}-U^{\prime}(.) C^{\prime \prime}\left(S_{i}\right)\right] H_{p} } \\
& -U^{\prime \prime}(.)\left(p-C^{\prime}\left(S_{i}\right)+m_{i}\left(P^{R}-p\right)\right)\left(S_{i}-Q C_{i}-m_{i} S+m_{i}\left(P^{R}-p\right) Q\right) \frac{1}{Q} H_{p} \\
& -U^{\prime}(.)\left(1-m_{i}\right) \frac{1}{Q} H_{p}
\end{aligned}
$$

Again, from the first order condition, $p-C^{\prime}\left(S_{i}\right)+m_{i}\left(P^{R}-p\right)=\frac{1}{Q}\left(S_{i}-\right.$ $\left.Q C_{i}-m_{i} S+m_{i}\left(P^{R}-p\right) Q\right)$. Hence, the first and third term cancel out.

Then,

$$
\begin{aligned}
Z_{q} & =-U^{\prime}(.) C^{\prime \prime}\left(S_{i}\right) H_{p}-U^{\prime}(.)\left(1-m_{i}\right) \frac{1}{Q} H_{p} \\
& =-\left[C^{\prime \prime}\left(S_{i}\right)+\left(1-m_{i}\right) \frac{1}{Q}\right]<0
\end{aligned}
$$

Recall that in equilibrium $Q=\frac{K(K-2)}{b(K-1)}$. Given $0 \leq m_{i} \leq 1$, the sufficient condition for a local (global) maximum is that, for any point on the curve, the utility functions are increasing $U^{\prime}>0$ and $C^{\prime \prime}=b>0$ (which implies $Q>0$ ). 


\section{C.3 Equilibrium result}

Consider the assumptions of proposition 2.3 and equations (26-27). Substituting and suppressing time subscript $t$, we have:

$$
\begin{aligned}
& p-a-\sum_{j=1}^{L} \rho_{j} w_{j}-b S_{i}=\frac{Q C_{i}+m_{i} D-S_{i}}{-(K-1) \alpha} \\
& (K-1) \alpha p-(K-1) \alpha a-(K-1) \alpha \sum_{j=1}^{L} \rho_{j} w_{j t}+Q C_{i}+m_{i}\left(c-\kappa_{o} p^{R}+\sum_{j=1}^{L} \kappa_{j} w_{j t}\right) \\
& =S_{i}(p)[1+(K-1) \alpha b] .
\end{aligned}
$$

Reorganizing equations we have:

$$
\begin{aligned}
& m_{i}\left(c-\kappa_{o} p^{R}\right)-(K-1) \alpha a+(K-1) \alpha p-\sum_{j=1}^{L}\left((K-1) \alpha \rho_{j}-m_{i} \kappa_{j}\right) w_{j t}+Q C_{i} \\
& =\left(\psi_{i}+\alpha p+\beta Q C_{i}+\sum_{j=1}^{L} \delta_{i j} w_{j}\right)[1+(K-1) \alpha b],
\end{aligned}
$$

which implies that the following must hold for $i=1,2, \ldots N$ :

$$
\begin{aligned}
& \frac{(K-1) \alpha}{1+(K-1) \alpha b}=\alpha \\
& \frac{+m_{i}\left(c-\kappa_{o} p^{R}\right)-a(K-1) \alpha}{1+(K-1) \alpha b}=\psi_{i} \\
& \frac{1}{1+(K-1) \alpha b}=\beta \\
& -\frac{\rho_{1}(K-1) \alpha-m_{i} \kappa_{1}}{1+(K-1) \alpha b}=\delta_{i 1} \\
& -\frac{\rho_{2}(K-1) \alpha-m_{i} \kappa_{2}}{1+(K-1) \alpha b}=\delta_{i 2} \\
& \vdots \\
& -\frac{\rho_{L}(K-1) \alpha-m_{i} \kappa_{L}}{1+(K-1) \alpha b}=\delta_{i L}
\end{aligned}
$$

Solving the system and substituting back into the assumed general supply function,

$$
\begin{aligned}
S_{i t}\left(p_{t}, Q C_{i t}, \vec{W}_{t}\right)= & -\frac{a(K-2)}{b(K-1)}+\frac{K-2}{b(K-1)} p_{t}+\frac{1}{K-1} Q C_{i t} \\
& +\frac{m_{i}}{K-1} D_{t}\left(p_{t}^{R}, \vec{W}_{t}\right)-\frac{(K-2)}{b(K-1)} \sum_{j=1}^{L} \rho_{j} w_{j t} \\
D_{t}\left(p_{t}^{R}, \vec{W}_{t}\right)= & c-\kappa_{o} p^{R}+\sum_{j=1}^{L} \kappa_{j} w_{j t} .
\end{aligned}
$$


Clearing the market and putting in terms of $p_{t}^{c}$,

$$
\begin{aligned}
p_{t}^{c}= & a+b \frac{\left(c-\kappa_{o} p^{R}\right)\left(K-\left(1+\sum_{i=1}^{K} m_{i}\right)\right)}{K(K-2)}-\frac{b}{K(K-2)} \sum_{i=1}^{K} Q C_{i t} \\
& +\sum_{j=1}^{L}\left(\rho_{j}+b \frac{\left(K-\left(1+\sum_{i=1}^{K} m_{i}\right)\right)}{K(K-2)} \kappa_{j}\right) w_{j t},
\end{aligned}
$$

which is the same as:

$$
p_{t}^{c}=A-B \sum_{i=1}^{K} Q C_{i t}^{*}+\sum_{j=1}^{L} C_{j} w_{j t},
$$

where

$$
\begin{aligned}
A & =a+b \frac{\left(c-\kappa_{o} p^{R}\right)\left(K-\left(1+\sum_{i=1}^{K} m_{i}\right)\right)}{K(K-2)} \\
B & =\frac{b}{K(K-2)} \\
C_{j} & =\rho_{j}+b \frac{\left(K-\left(1+\sum_{i=1}^{K} m_{i}\right)\right)}{K(K-2)} \kappa_{j} .
\end{aligned}
$$

\section{Proof of corollary 3.2}

Consider $a \geq 0, b \geq 0, \rho \geq 0, \mu \geq 0, \psi \geq 0$ and $f(T) \geq 0 \forall T$.

We have:

$$
\begin{aligned}
& \frac{\partial P C\left(p_{t}, T\right)}{\partial a}=1 \geq 0 \\
& \frac{\partial P C\left(p_{t}, T\right)}{\partial x_{1 t}}=\frac{b(K-1-M)}{K(K-2)} e^{-\frac{b(K-1-M)}{K(K-2)} \psi(T-t)} \geq 0 \\
& \frac{\partial P C\left(p_{t}, T\right)}{\partial w_{2}}=\rho \geq 0 \\
& \frac{\partial P C\left(p_{t}, T\right)}{\partial \mu}=\rho(T-t) \geq 0 \\
& \frac{\partial P C\left(p_{t}, T\right)}{\partial \sigma_{1}}=-\left(1-e^{-\frac{b(K-1-M)}{K(K-2)} \psi(T-t)}\right) \frac{\lambda_{1}}{\psi} \leq 0 \\
& \frac{\partial P C\left(p_{t}, T\right)}{\partial \lambda_{1}}=-\left(1-e^{-\frac{b(K-1-M)}{K(K-2)} \psi(T-t)}\right) \frac{\sigma_{1}}{\psi} \leq 0 \\
& \frac{\partial P C\left(p_{t}, T\right)}{\partial \sigma_{2}}=-\rho \lambda_{2}(T-t) \leq 0 \\
& \frac{\partial P C\left(p_{t}, T\right)}{\partial \lambda_{2}}=-\rho \sigma_{2}(T-t) \leq 0 .
\end{aligned}
$$

